\title{
Cyclic olefin polymer as a novel membrane material for membrane distillation applications
}

M. Sabzekar ${ }^{\mathrm{a}, \mathrm{b}}$, M. Pourafshari Chenar ${ }^{\mathrm{a},{ }^{*}}$, Z. Maghsoud ${ }^{\mathrm{a}}$, O. Mostaghisi ${ }^{\mathrm{c}}$, M.C. García-Payo ${ }^{\mathrm{b}}$, M. Khayet $^{\mathrm{b}, \mathrm{d}, *}$

${ }^{a}$ Department of Chemical Engineering, Faculty of Engineering, Ferdowsi University of Mashhad, Mashhad, Iran

${ }^{\mathrm{b}}$ Department of Structure of Matter, Thermal Physics and Electronics, Faculty of Physics, University Complutense of Madrid, Avda. Complutense s/n, 28040 Madrid, Spain

${ }^{\mathrm{c}}$ Sarkhoon Gas Refinery Company, Bandar abbas, Iran

${ }^{\mathrm{d}}$ Madrid Institute for Advanced Studies of Water (IMDEA Water Institute), Avda. Punto Com no. 2, Alcalá de Henares, 28805 Madrid, Spain

* Corresponding authors: khayetm@fis.ucm.es (M. Khayet)

Pourafshari@um.ac.ir (M. Pourafshari Chenar) 


\begin{abstract}
A first attempt was made to prepare cyclic olefin polymer/copolymer (COP/COC) flat-sheet porous membranes by the well-known non-solvent induced phase separation method. In this study, two solvents (chloroform and 1,2,4-trichlorobenzene), different additives (polyvinylpyrrolidone, PVP, polyethylene glycol, PEG400, polyethylene oxide, PEO, and Sorbitan monooleate, Span 80) and coagulants (acetone and 70/30 wt\% acetone/water mixture) were employed. The prepared membranes were characterized in terms of the thickness (70 - $85 \mu \mathrm{m})$, porosity ( 50 - 80\%), liquid entry pressure (1.16 - $4.55 \mathrm{bar})$, water contact angle $\left(\sim 86^{\circ}-111^{\circ}\right)$, mean pore size $(158-265 \mathrm{~nm})$, mechanical properties (tensile strength: 0.74 -5.51 MPa, elongation at break: 3.34\% -7.94\% and Young's modulus: 29 - $237 \mathrm{MPa}$ ), morphological and topographical characteristics. Short-term direct contact membrane distillation (DCMD) tests showed maximum permeate fluxes of $20 \mathrm{~kg} \cdot \mathrm{m}^{-}$ ${ }^{2} \mathrm{~h}^{-1}$ and $15 \mathrm{~kg} \cdot \mathrm{m}^{-2} \mathrm{~h}^{-1}$ when using as feed distilled water and $30 \mathrm{~g} / \mathrm{L}$ sodium chloride aqueous solution, respectively, with a high salt separation factor (99.99\%). Long-term DCMD tests of some selected membranes carried out during 24 - 50 h showed that the membranes prepared with PEG additive exhibited more stable DCMD performance. In general, it was proved that COP can be successfully used as a novel polymer candidate in membrane distillation (MD) applications.
\end{abstract}

Keywords: Cyclic Olefin Polymer (COP); porous flat-sheet membrane; non-solvent induced phase separation; additive; direct contact membrane distillation. 


\section{Introduction}

Water scarcity, one of the most critical issues of modern human life, has led many scientists to focus on water desalination and industrial wastewater reuse. Membrane-based technologies such as reverse osmosis (RO) and thermal desalination technologies such as multi effect distillation (MED) and multistage flash distillation (MSF) are currently being used. Compared to MED and MSF, RO is the preferred technology as it contributes with more than $60 \%$ in the desalination market. However, RO technology suffers some drawbacks such as its inability to treat high saline waters, brine discharge to the environment and high operating pressure requirement [1].

Membrane distillation (MD) is a non-isothermal separation technology, attractive in the field of desalination for its ability to treat high salinity water (up to $220 \mathrm{~g} / \mathrm{L} \mathrm{NaCl}$ ) including $\mathrm{RO}$ brine up to its saturation [2]. Among other advantages, it exhibits $~ 100 \%$ rejection of non-volatile solutes and it can be easily integrated with renewable energy systems. Moreover, very low hydrostatic pressures, near atmospheric pressure, are applied. In MD technology, various configurations have been proposed. By applying either a temperature difference between both sides of a porous hydrophobic membrane (i.e. a hot feed and a cold permeate) or vacuum in the membrane permeate side, a transmembrane water vapor pressure difference is established giving rise to distinct MD variants (direct contact membrane distillation, DCMD; vacuum membrane distillation, VMD; air gap membrane distillation, AGMD; sweeping gas membrane distillation, SGMD, etc.). In all these configurations, only water vapor is transported through the membrane pores that must be maintained dry as the applied transmembrane hydrostatic pressure is lower than the water liquid entry pressure $(L E P)$ of the membrane [3]. It is worth quoting that although the membrane has an important effect on the process efficiency, most MD studies have been focused on either theoretical modelling or the influence of different operating parameters on MD performance [4,5]. Only 
1 during last decade, efforts have been done on MD membrane and module engineering [6]. Various

2 innovative designs and novel membranes have been proposed for MD applications [7]. The MD

3 membranes should exhibit high hydrophobicity or omniphobicity to reduce the risk of pore wetting

4 by increasing the liquid entry pressure (LEP), high porosity to increase membrane permeability,

5 optimized thickness and low thermal conductivity to enhance thermal efficiency, high chemical

6 resistance and good thermal stability using appropriate materials to guarantee long-term membrane

7 performance [8-10].

8 The hydrophobic polymers proposed for the preparation of MD membranes are polypropylene

9 (PP) [11], polytetrafluoroethylene (PTFE) [12], PTFE-co-hexafluoropropylene (FEP) [13],

10 polyethylene (PE) [14], polyvinylidene fluoride (PVDF) [15] and its derivatives (PVDF-co-

11 tetrafluoroethylene (PVDF-TFE), PVDF-co-hexafluoropropylene (PVDF-HFP), PVDF-co-

12 trifluorochloroethylene (PVDF-CTFE)) [16-18] which are fabricated by different processes. Some

13 polymers such as PVDF have good processability by which the porous structure can be prepared

14 via non-solvent induced phase separation (NIPS). However, others such as PP and PE are subjected

15 to thermally induced phase separation (TIPS), and polymers such as PTFE and FEP need sintering

16 and melt spinning, respectively [19].

17 Cyclic olefin polymers are relatively new types of olefin polymers and consequently show the 18 characteristics of polyolefins. Cyclic olefin polymers exhibit interesting characteristics such as 19 their high glass transition temperature $\left(T_{g}: 80-180^{\circ} \mathrm{C}\right)$ in combination with excellent transparency, 20 good mechanical properties, low moisture absorption, low density, strength and hardness, little 21 shrinkage, good electrical properties, low thermal conductivity $\left(0.12-0.15 \mathrm{~W} \cdot \mathrm{m}^{-1} \cdot \mathrm{K}^{-1}\right)$, very good

22 melt processability, biocompatibility and chemical resistance to acids, alkalis and polar organic 23 solvents. These characteristics are attractive in different fields including packaging, optics and 
1 medical tools. Cyclic olefin copolymer (COC), the copolymer of ethylene and norbornene, and

2 cyclic olefin polymer (COP) are relatively new types of olefin polymers, although the first

3 commercial product of COC appeared by the end of 1980s [20]. In 1984, Yamazaki et al. [21]

4 from Zeon company in Japan developed a particular type of COP containing only norbornene,

5 which has a rigid bridged-ring structure preventing crystallization. As can be seen in Fig.1, the

6 structure of COP and COC are very similar [20].

7

8

9

10

11

12

13

14

15

16

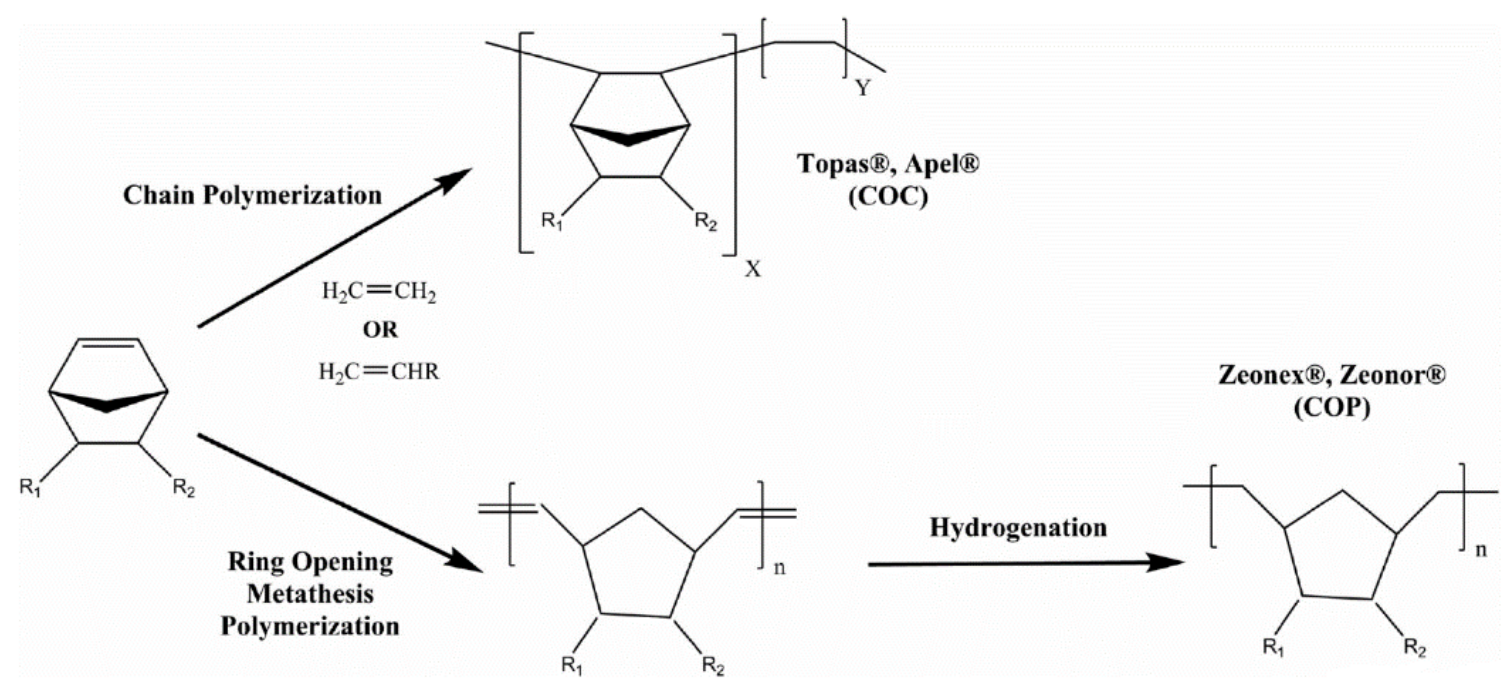

Fig.1. Synthesis of cyclic olefin copolymers (COC) and cyclic olefin polymers (COP) from norbornene [20].

It must be pointed out that there are very few reports on COC membranes and all of them deal with dense membranes [22,23]. For instance, gas transport, sorption properties and selectivity of a series of COC dense membranes prepared with different contents of norbornene (40-66\%) were investigated for the first time by $\mathrm{Hu}$ et al. [22]. It was found that the norbornene content had a significant effect on the gas performance of dense COC membrane. Moreover, its fractional free volume increased with the norbornene content resulting in higher solubility and permeability. It was claimed that COC could be a suitable membrane material for the separation of $\mathrm{O}_{2} / \mathrm{N}_{2}$ at 
1 moderate pressures, less than 10 bar. Afterwards, Doğu and Ercan [23] evaluated the gas

2 permeability and selectivity of COC composite membranes for $\mathrm{H}_{2} / \mathrm{CO}_{2}$ and $\mathrm{H}_{2} / \mathrm{CH}_{4}$ separations.

3 These COC composite membranes were prepared by the melt processing method using different

4 types of graphite nano-sheets. The $\mathrm{O}_{2} / \mathrm{N}_{2}$ ideal selectivity was found to be higher than that of other

5 traditional membrane materials and the permeability-selectivity tradeoff limit (Robeson's 2008

6 upper bound) was surpassed for $\mathrm{H}_{2} / \mathrm{CO}_{2}$ separation.

7 To the best of our knowledge, there is no documentation about COP and COC porous

8 membranes. In this work, we propose for the first time the use of COP and COC to prepare porous

9 membranes by NIPS method for different applications especially membrane distillation (MD). It

10 is worth quoting that COP is a cheap and plastic polymer used for the first time as a membrane

11 material. In this study, 5 steps were followed as shown in Fig.2 to investigate the effects of

12 polymers, solvents, additive's concertation and type, and coagulants on the resultant membranes.

13 The membranes were characterized by various techniques and the obtained results were compared

14 with other membranes used in desalination by DCMD. 


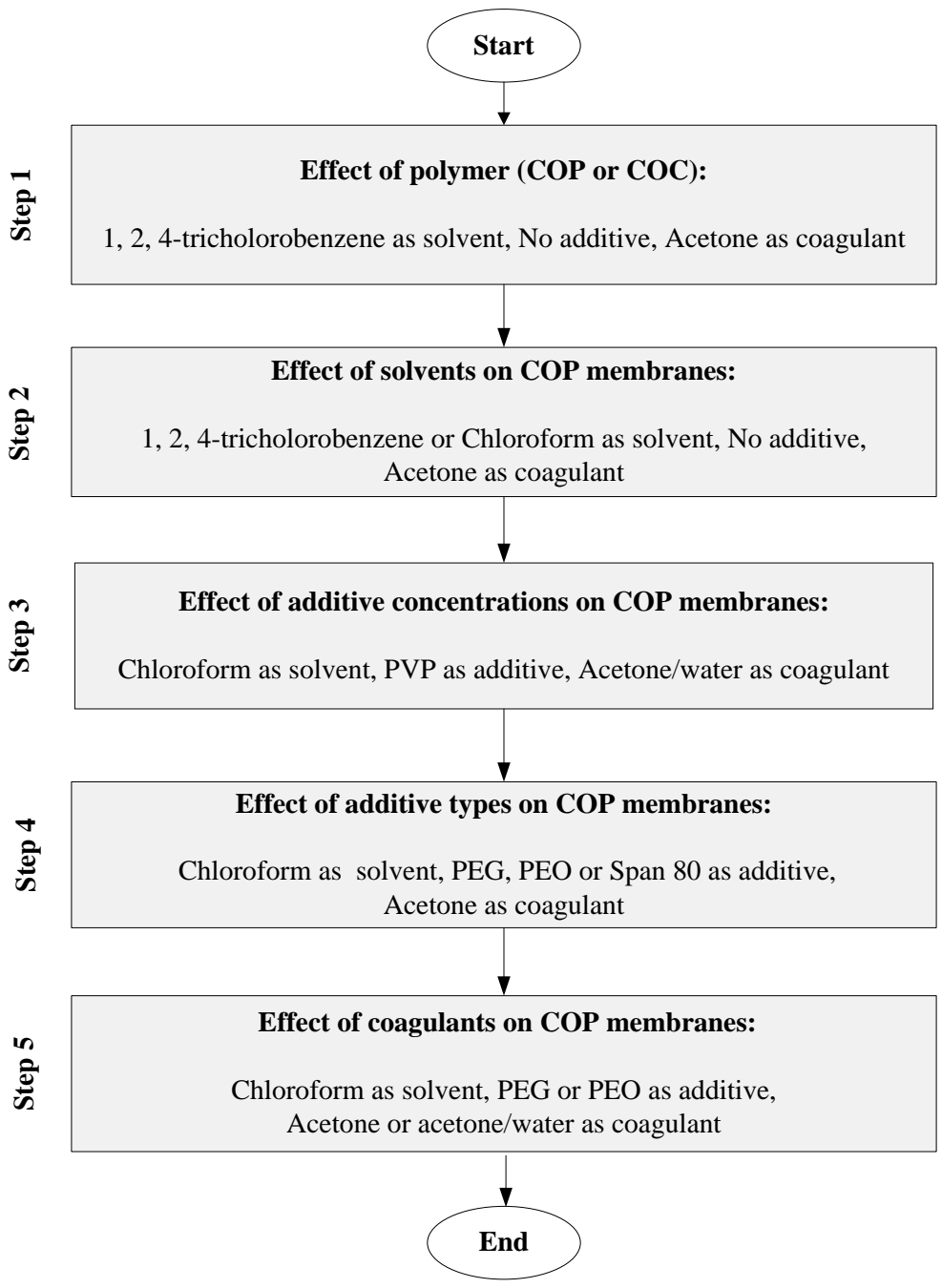

Fig. 2. Schematic summary of the research study.

\section{2. Experimental}

$4 \quad$ 2.1. Materials

5 Cyclic olefin copolymer, Topas ${ }^{\circledR}$ 6013, and cyclic olefin polymer, Zeonex ${ }^{\circledR}$ 480R, were 6 commercial grades and kindly donated by Topas Advanced Polymers GmbH and Zeon Europe

7 GmbH (Germany), respectively. Their properties are shown in Table 1. Other used chemicals in

8 this study include chloroform and 1,2,4-Trichlorobenzene as solvents, acetone as a non-solvent, 9 Polyethylene glycol (PEG), Polyethylene oxide (PEO), Polyvinylpyrrolidone K90 (PVP) and, 
1 Sorbitan monooleate (Span ${ }^{\circledR}$ 80), as additives. Isopropyl alcohol (IPA) and POREFIL ${ }^{\circledR}$ were

2 employed as wetting liquids for the measurements of porosity and porometry, respectively.

3 Sodium chloride $(\mathrm{NaCl})$ and distilled water were used to prepare the salt aqueous feed solutions

4 for DCMD experiments. The characteristics of these materials together with their corresponding

5 suppliers are listed in Table 2.

6 Table 1. Properties of COP used in this study.

\begin{tabular}{ccccc}
$\begin{array}{c}\text { Commercial } \\
\text { grade }\end{array}$ & $\begin{array}{c}\text { Norbornene units } \\
\mathbf{( \% )}\end{array}$ & $\begin{array}{c}\boldsymbol{T}_{\mathbf{g}}{ }^{\mathbf{a}} \\
\left.\mathbf{(}^{\circ} \mathbf{C}\right)\end{array}$ & $\begin{array}{c}\boldsymbol{\rho}^{\mathbf{a}} \\
\left(\mathbf{g} / \mathbf{c m}^{\mathbf{3}}\right)\end{array}$ & $\begin{array}{c}\mathbf{M F I}^{\mathbf{a}} \\
\mathbf{( g / 1 0 ~} \mathbf{m i n})\end{array}$ \\
\hline Topas $^{\circledR} 6013$ & 54.3 & 140 & 1.02 & $12^{\mathrm{b}}$ \\
Zeonex $^{\circledR} 480 \mathrm{R}$ & 100 & 137 & 1.01 & $21^{\mathrm{c}}$ \\
\hline
\end{tabular}

$7 \quad{ }^{a}$ MFI: melt flow index; $T_{g}$ : glass transition temperature; $\rho$ : density.

$8 \quad$ b at $260^{\circ} \mathrm{C}$ and $2.16 \mathrm{~kg}$

$9 \quad{ }^{\mathrm{C}}$ at $280^{\circ} \mathrm{C}$ and $2.16 \mathrm{~kg}$

10 Table 2. List of used chemicals and solvents.

\begin{tabular}{ccc} 
Material & Characteristics & Supplier \\
\hline PEG & average $M_{n}: 400 \mathrm{~g} / \mathrm{mol}$ & Sigma-Aldrich \\
PEO & $M_{W}: 200,000-300,000 \mathrm{~g} / \mathrm{mol}$ & Sigma-Aldrich \\
PVP & $M_{W}: 360,000 \mathrm{~g} / \mathrm{mol}$ & Fluka Chemie AG \\
Span ${ }^{\circledR} 80$ & non-ionic surfactant & Sigma-Aldrich \\
Chloroform & ACS reagent, puriss., $\geq 99.8 \%$, & Acros Organics \\
stabilized with ethanol & Anhydrous, puriss., $\geq 99 \%$ & Sigma-Aldrich \\
1,2,4-Trichlorobenzene & Puriss., $\geq 99.5 \%$, for analysis & Acros organics \\
Acetone & Chemical nature: pefluoroether & \\
& Surface tension: $16 \mathrm{mN} / \mathrm{m}$ & Vapor pressure: $3.33 \mathrm{~Pa}$ \\
POREFIL ${ }^{\circledR}$ & Viscosity: $4.4 \mathrm{mPa}$ s & Porometer \\
& Anhydrous, puriss., $\geq 99.5 \%$ & Sigma-Aldrich \\
IPA & PanReac & AppliChem GmbH \\
\hline
\end{tabular}


2 The solvent (chloroform or 1,2,4-trichlorobenzene) was mixed with the additive (0.1, 0.2 or

$30.3 \mathrm{wt} \%)$ for $1 \mathrm{~h}$ at room temperature $\left(22^{\circ} \mathrm{C}\right)$ using a magnetic stirrer at $120 \mathrm{rpm} .10 \mathrm{wt} \%$ of

4 polymers (COP, COC) was then added to the solution that was subsequently kept on the orbital

5 shaker at $40^{\circ} \mathrm{C}$ and $100 \mathrm{rpm}$ for almost $12 \mathrm{~h}$ until it became a homogeneous solution. Finally, the

6 obtained polymer dope solution was degassed for $4 \mathrm{~h}$ at room temperature followed by casting

7 onto a glass plate by using an automatic film applicator (Elcometer 4340, Elcometer ${ }^{\circledR}$ ) with a knife

8 gap of $0.25 \mathrm{~mm}$ and a velocity of $100 \mathrm{~mm} / \mathrm{s}$ at room temperature $\left(22^{\circ} \mathrm{C}\right)$. The cast film was

9 immediately immersed in the non-solvent coagulation bath (acetone or 70/30 wt\% acetone/water

10 mixture) at room temperature. The flat-sheet membrane was taken out from the coagulants and

11 rinsed with acetone/water mixture (70/30 wt\%) to remove any residual solvent or additives.

12 Finally, the membrane was air-dried for 24 h. Table 3 summarizes the different used solvents,

13 coagulants, additives and their concentrations. The membrane code was based on the used

14 polymers, solvents, additives, content of additive (wt\%) and coagulants. For instance, the

15 membrane PVP-0.2-AW means that it was prepared with chloroform as solvent, PVP as additive

16 with 0.2 wt\% and acetone/water as coagulants. All COP membranes were prepared with

17 chloroform solvent except the membrane TCB-NA-A that was prepared with 1,2,4-

18 Trichlorobenzene. The COC membrane was also prepared with TCB and named as COC-TCB-

19 NA-A. 
1 Table 3. Dope solution compositions and process parameters for the prepared membranes.

\begin{tabular}{cccccc}
\hline Membrane code & Solvent & Additive & $\begin{array}{c}\text { Additive content } \\
\text { (wt \%) }\end{array}$ & $\begin{array}{c}\text { Solvent content } \\
\text { (wt \%) }\end{array}$ & Coagulant \\
\hline COC-TCB-NA-A & TCB $^{\mathrm{a}}$ & - & - & 90 & Acetone \\
TCB-NA-A & TCB & - & - & 90 & Acetone \\
CF-NA-A & CF $^{\mathrm{b}}$ & - & - & 90 & Acetone \\
PVP-0.1-AW & CF & PVP & 0.1 & 89.9 & Acetone/water \\
PVP-0.2-AW & CF & PVP & 0.2 & 89.8 & Acetone/water \\
PVP-0.3-AW & CF & PVP & 0.3 & 89.7 & Acetone/water \\
PEG-0.2-A & CF & PEG & 0.2 & 89.8 & Acetone \\
PEG-0.2-AW & CF & PEG & 0.2 & 89.8 & Acetone/water \\
PEO-0.2-A & CF & PEO & 0.2 & 89.8 & Acetone \\
PEO-0.2-AW & CF & PEO & 0.2 & 89.8 & Acetone/water \\
Span 80-0.2-A & CF & Span 80 & 0.2 & 89.8 & Acetone \\
\hline
\end{tabular}

2 a 1,2,4-trichlorobenzene, ${ }^{\mathrm{b}}$ chloroform, ${ }^{\mathrm{c}}$ 70/30 wt\% in all experiments.

\section{$3 \quad$ 2.3. Membrane characterization}

4 Different characterization techniques were applied to determine the characteristics of the 5 prepared membranes and the results were compared to the general properties of the MD 6 membranes.

7 The morphological structure of both the surface and cross-section of the membranes was 8 investigated by the field emission scanning electron microscope (FE-SEM, MIRA3 TESCAN,

9 Czech Republic) operating at $10 \mathrm{kV}$ acceleration voltage. Previously, the cross-section of the 10 samples was prepared by fracturing in liquid nitrogen. The membrane surface and the prepared 
cross-section was sputter-coated by a thin gold layer using a sputter coater (Q150R S, Quorum,

2 England)) during $60 \mathrm{~s}$ under $20 \mathrm{~mA}$.

3 The membrane thickness was measured at 30 different spots on each sample using a micrometer

4 equipped with a feeler (ISL Isocontrol). The average value of the measured thicknesses with their 5 corresponding standard deviation was reported as the final thickness of each sample.

6 The hydrophobicity of the membrane surface was analyzed by water contact angle measurement.

7 This was carried out at room temperature using a computerized optical system CAM100, equipped

8 with a CCD camera, frame grabber and image analysis software CAM200usb. More information

9 can be found elsewhere [24]. The volume of the drop was controlled by a Hamilton ${ }^{\circledR}$ glass syringe with a Hamilton ${ }^{\circledR}$ stainless steel needle, which was between 12 and $14 \mu \mathrm{L}$. Five images were 11 recorded during $4 \mathrm{~s}$ for each drop and at least 10 drops were considered for each sample to 12 determine the average water contact angle $(\theta)$ value together with its standard deviation.

13 The void volume fraction (i.e. porosity, $\varepsilon$ ) of the flat-sheet membranes was determined by 14 measuring the density of the membrane material ( $\left.\rho_{p o l}\right)$ using isopropyl alcohol (IPA) and the 15 density of the membrane $\left(\rho_{m}\right)$ using distilled water following the method described in [25]. 16 According to this method, the weight of a pre-weighed sample was measured first in a water (dry 17 membrane) and then in IPA (wetted membrane) by using a pycnometer. Finally, the porosity of 18 sample was calculated based on the obtained density of the membrane material from the weight in 19 IPA and the density of the membrane from the weight in water. The reported data for each 20 membrane is the average of at least three measurements of different samples.

21 The membrane mean pore size was determined via wet/dry flow method using a gas-liquid 22 displacement Porometer and its corresponding computer software (POROLUX ${ }^{\mathrm{TM}}$ 100, Porometer). 23 Briefly, the flat-sheet membrane was first wetted by a wetting liquid (POREFIL ${ }^{\circledR}$ ) and the gas 
1 permeation flow (compressed air) was measured at room temperature for different transmembrane

2 increasing hydrostatic pressures (0-0.7 MPa) to obtain the S-shaped wet curve. Subsequently, the

3 dry curve was obtained by measuring the air flow rate under different transmembrane hydrostatic

4 pressures through the dry sample. Both the cumulative filter flow (CFF) and the differential filter

5 flow $(D F F)$ curves were obtained using the above mentioned software. For each membrane, at

6 least three tests were carried out. The followed procedure was described elsewhere [24,26].

7 The liquid entry pressure ( $L E P)$ of the membrane is the minimum hydrostatic pressure applied

8 on the flat-sheet membrane before the liquid penetrates inside its pores. This was measured for

9 distilled water according to the procedure and set-up described in [27]. These measurements were

10 carried out using three different membrane samples and the average values together with their

11 standard deviations were calculated.

12 The mechanical properties of the membranes were evaluated by measuring the tensile strength, 13 elongation at break, and Young's modulus using a universal tensile tester (SANTAM STM20)

14 equipped with a $6 \mathrm{~N}$ load cell, according to ASTM D 882. The tests were carried out at room

15 temperature, a crosshead speed of $5 \mathrm{~mm} / \mathrm{min}$ on rectangular membrane strips with dimensions of

$1650 \mathrm{~mm} \times 10 \mathrm{~mm}$. The thickness of each membrane sample was measured and considered in the

17 calculation of the cross-sectional area to determine the tensile strength. For each membrane, five

18 samples were considered and the average values together with their standard deviations were 19 calculated.

20 Atomic force microscopy (AFM) was carried out to study the surface topographical structure 21 and determine the roughness parameters (average roughness, $R_{a}$, and root mean square (RMS)

22 roughness, $R_{q}$ ) of both the top and bottom surfaces of the membranes using an Atomic Force 23 Microscope (AFM, Ara research, model: Full plus). $R_{a}$ is defined as the arithmetic average of the 
1 absolute values of the surface height deviations measured from the mean plane and $R_{q}$ is the root

2 mean square average of the height deviations taken from the center plane. The measurements were

3 conducted at room temperature over an area of $5 \mu \mathrm{m} \times 5 \mu \mathrm{m}$.

\section{$4 \quad$ 2.4. Direct contact membrane distillation (DCMD)}

5 The DCMD performance of the membranes were evaluated using two experimental set-ups,

6 one for short-term experimental tests and the other for long-term experimental tests.

\section{$7 \quad$ 2.4.1. Short-term experiments}

The short-term experiments of all COP membranes was carried out using the DCMD set-up

9 schematized in Fig. 3. The permeate flux was measured using distilled water $\left(J_{w}\right)$ and $30 \mathrm{~g} / \mathrm{L} \mathrm{NaCl}$

10 aqueous solution $(J)$ as feed together with the salt separation factor $(\alpha)$. This system consists of

11 two double-wall stainless steel cylindrical chambers $(250 \mathrm{~mL})$. The temperature inside each

12 chamber was measured by temperature sensor (Pt-100) having an accuracy of $\pm 0.1 \mathrm{~K}$. The feed

13 and permeate were stirred at $700 \mathrm{rpm}$ using a magnetic stirrer connected to a graduated motor. The

14 membrane with the effective area of $8.3 \mathrm{~cm}^{2}$ was placed between the two chambers. To measure

15 the distilled water permeate flux $\left(J_{w}\right)$ both chambers were filled with distilled water. A checking

16 leak test was carried out first by stirring distilled water in both the feed and permeate chambers at

17 the same temperature (room temperature, $22^{\circ} \mathrm{C}$ ). This guarantees that no liquid water is transferred

18 between the chambers and the hydrophobicity of the membrane is acceptable. A heating and a

19 cooling system were connected to both chambers to control the feed and permeate temperatures at

$2070{ }^{\circ} \mathrm{C}$ and $25^{\circ} \mathrm{C}$, respectively. Then desalination test was performed. In this test, the feed chamber 
1 was filled with salt solution and both the permeate flux $(J)$ and the salt separation factor $(\alpha)$ were

2 calculated using the following equations:

$$
\begin{aligned}
J & =\frac{\Delta m}{S . \Delta t} \\
\alpha & =100 \times\left(1-\frac{C_{p}}{C_{f}}\right)
\end{aligned}
$$

3 where $\Delta m$ is the registered mass of the produced water over time ( $\Delta t), S$ is the surface area of the

4 membrane, and $C_{p}$ and $C_{f}$ are the salt concentration of the permeate and feed, respectively, calculated

5 from the previously calibration of the salt concentration versus the electrical conductivity. The electrical

6 conductivity of the feed and permeate solutions were measured at the beginning and at the end of

7 each DCMD test by a previously calibrated conductivity meter (Mettler-Toledo GmbH,

8 SevenCompact S230). Two electrical conductivity sensors along with a temperature sensor

9 InLab ${ }^{\circledR} 731$-ISM and InLab ${ }^{\circledR} 741$-ISM were used to analyze the salt content of the feed and 10 permeate, respectively. With both sensors, a wide range of electrical conductivity $(0.000 \mu \mathrm{S} / \mathrm{cm}$ -

$111000 \mathrm{mS} / \mathrm{cm}$ ) could be measured. The resolutions of the mentioned sensors for the permeate and

12 feed are in the range of $0.001 \mu \mathrm{S} / \mathrm{cm}$ and $0.01 \mathrm{mS} / \mathrm{cm}$, respectively. The electrical conductivity of

13 the permeate and feed at the beginning of each experiment was measured as $0.972 \pm 0.001 \mu \mathrm{S} / \mathrm{cm}$ 14 and $48.96 \pm 0.01 \mathrm{mS} / \mathrm{cm}$, respectively. 


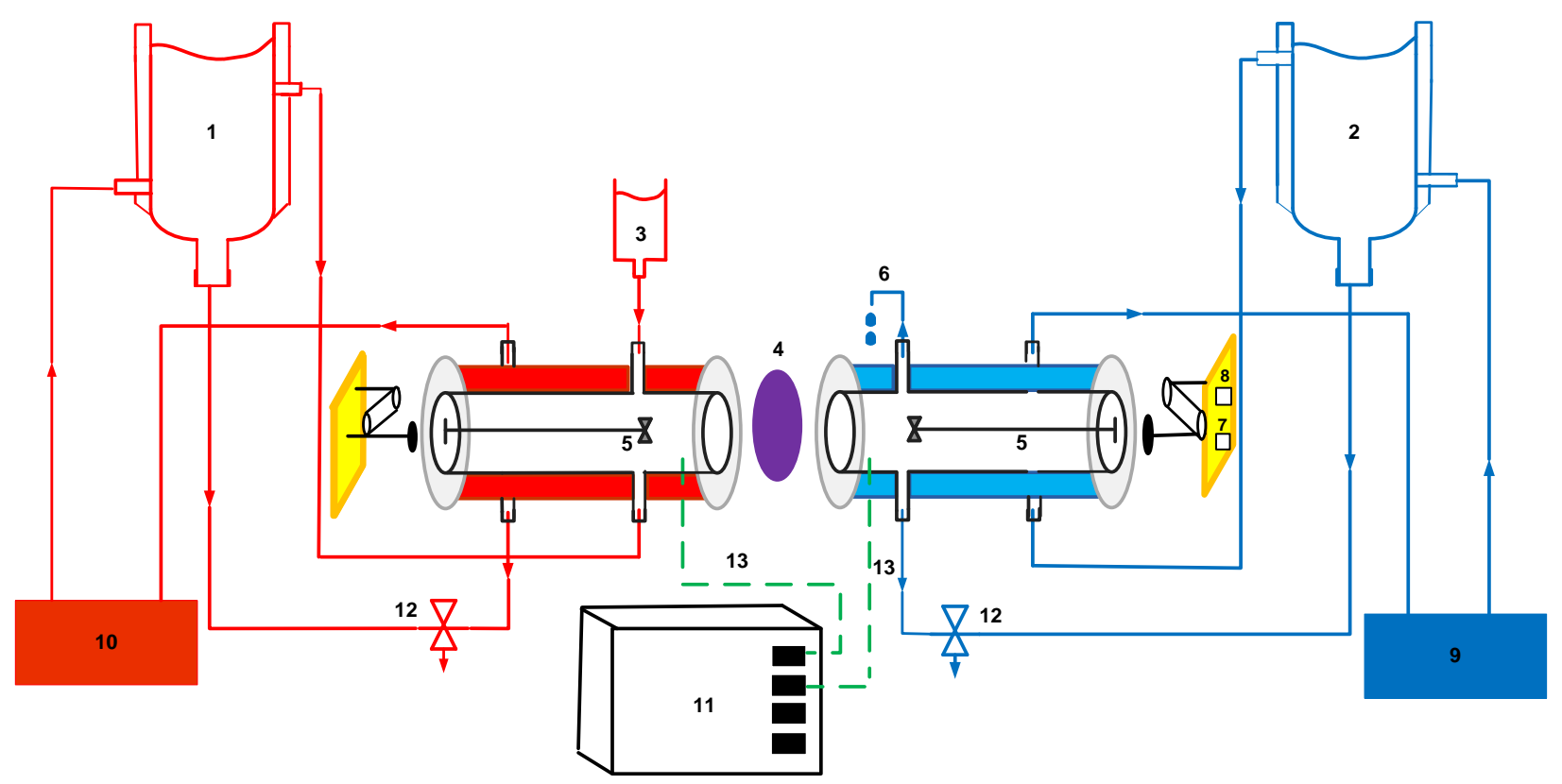

2 Fig. 3. DCMD short-term experiment set-up: (1) feed container, (2) permeate container, (3) feed 3 supplier during DCMD test, (4) membrane holder, (5) stirrers, (6) pipette or tube for permeate flux

4 measurement, (7) stirring rate regulator, (8) stirring graduated motor, (9) chiller, (10) thermostat, 5 (11) temperature reader, (12) three way valves, (13) Pt-100 temperature sensors.

\subsubsection{Long-term experiments} performance during the previously taken short-term experimental tests. The DCMD set-up (Model No. FMD-SS-3090, M/s TECH INC, India) depicted in Fig. 4 was used. The effective membrane area of the rectangular module is $27 \mathrm{~cm}^{2}$. The DCMD experiment was carried out using $30 \mathrm{~g} / \mathrm{L}$

$11 \mathrm{NaCl}$ aqueous solution as feed and distilled water as permeate. The volume of the feed and

12 permeate tanks is $5 \mathrm{~L}$. Both the feed and permeate circulated at a flow rate of $30 \mathrm{~L} / \mathrm{h}$ using two 13 circulation pumps (TECH INC, India). Similar to the short-term experimental test, both the feed 14 and permeate tanks were connected to the heating and cooling systems to adjust the feed and 
1 permeate temperatures to 70 and $25^{\circ} \mathrm{C}$, respectively. During the DCMD test, the mass of the

2 produced water in the permeate tank was weighed every 60s using a digital balance

3 (ACCUMAX ${ }^{\mathrm{TM}}$ ) connected to a computer, which also permitted to record the inlet and outlet

4 temperatures of the membrane module. The separation factor was evaluated from the

5 measurements of the electrical conductivity of the feed and permeate solutions as stated

6 previously.
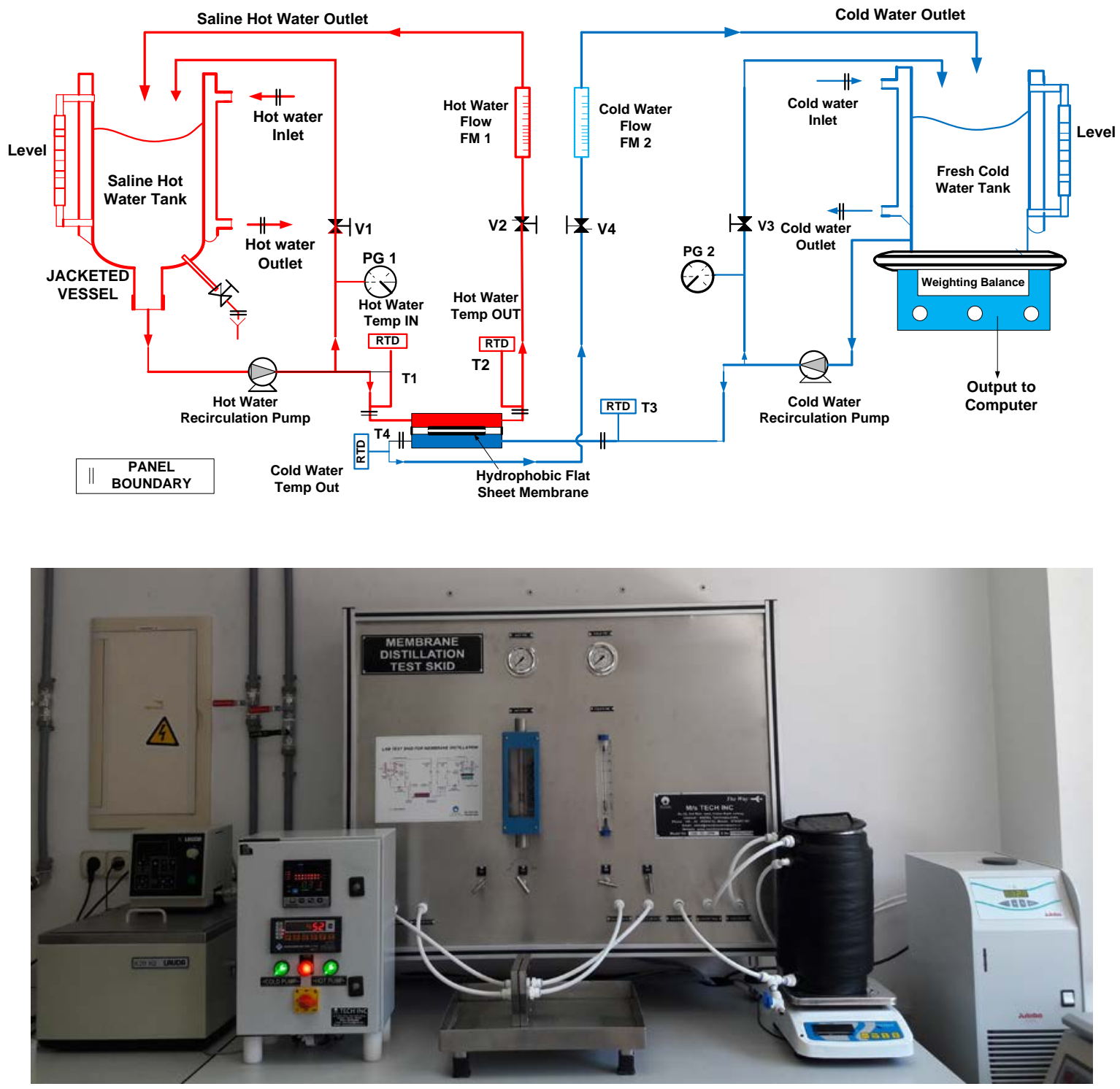

Fig. 4. Schematic and real images of the DCMD long-term experimental set-up. 


\section{Results and discussion}

2 3.1. Study of the affinity between polymer, solvent and non-solvent

$9 \quad \delta^{2}=\delta_{h}^{2}+\delta_{p}^{2}+\delta_{d}^{2}$

$R_{H S P}^{2}(N S-S)=4\left(\delta_{d_{N S}}-\delta_{d_{S}}\right)^{2}+\left(\delta_{p_{N S}}-\delta_{p_{S}}\right)^{2}+\left(\delta_{h_{N S}}-\delta_{h_{S}}\right)^{2}$

22 The lower is the $R_{H S P}$ (NS-S) value, the weaker is the coagulant for a polymer solution.

A suitable solvent for a given polymer should have a solubility parameter close to that of the polymer. Therefore, the Hansen solubility parameter distance $\left(R_{H S P}\right)$ is another measure to determine a good solvent $(S)$ for a given polymer $(P)$. $R_{H S P}$ can be calculated as follows:

$$
R_{H S P}^{2}(P-S)=4\left(\delta_{d P}-\delta_{d S}\right)^{2}+\left(\delta_{p P}-\delta_{p S}\right)^{2}+\left(\delta_{h P}-\delta_{h S}\right)^{2}
$$

More affinity between two chemicals is identified by a low $R_{H S P}$ value between them.

The HSP of mixed non-solvents can be determined as follows [29]:

$$
\left[\delta_{d_{N S}}, \delta_{p_{N S}}, \delta_{h_{N S}}\right]=\left[a \delta_{d 1}+b \delta_{d 2}, a \delta_{p 1}+b \delta_{p 2}, a \delta_{h 1}+b \delta_{h 2}\right] /(a+b)
$$

where the subscripts 1 and 2 are for each compound present in the non-solvent mixture (i.e. acetone and water) and $a$ and $b$ are the volume fractions of different components in the non-solvent mixture. Therefore, to select a coagulant for a given polymer solution, the $R_{H S P}$ (NS-S) parameter was considered as: 
The HSP components of all used pure materials are listed in Table 4 together with the

2 calculated $R_{H S P}$ values [28,30]. In the calculations of $R_{H S P}$ of P-S and NS-S, the HSP of the additive

3 was ignored because of its very small amount in the polymer solution and the HSP of COP was

4 assumed to be close to COC (Topas ${ }^{\circledR}$ 6013) [31]. Based on the obtained $R_{H S P}$ values, since the $R_{H S P}$

5 of P-CF (3.7) is lower than the $R_{H S P}$ of P-TCB (5.4), the polymer has more affinity to chloroform

6 than to 1,2,4- trichlorobenzene. Also, acetone-chloroform mixture ( $R_{H S P}$ of acetone-CF=8.7) is

7 more compatible compared to acetone/water-chloroform mixture $\left(R_{H S P}\right.$ of Acetone/water-

$8 \mathrm{CF}=11.1$ ) as shown in Table 4. So, it is expected that the exchange rate of solvent and non-solvent

9 in the acetone-chloroform mixture is faster than acetone/water-chloroform mixture.

11 Table 4. Solubility parameters of the used materials in this study with their corresponding $R_{H S P}$ 12 values.

\begin{tabular}{|c|c|c|c|c|c|c|c|c|c|}
\hline \multirow[t]{2}{*}{ Material type } & \multicolumn{4}{|c|}{ Solubility parameters $\left(\mathrm{MPa}^{1 / 2}\right)$} & \multicolumn{5}{|c|}{$R_{H S P}$} \\
\hline & $\delta_{d}$ & $\delta_{p}$ & $\delta_{h}$ & $\delta$ & P-S & NS-S & A-S & A-NS & A-NS $m$ \\
\hline $\begin{array}{c}\text { Polymer } \\
\text { (COP/COC) }\end{array}$ & 18.0 & 3.0 & 2.0 & 18.3 & - & - & & & \\
\hline $\begin{array}{c}1,2,4- \\
\text { Trichlorobenzene }\end{array}$ & 20.2 & 6.0 & 3.2 & 21.3 & 5.4 & $11.1^{\mathrm{a}}$ & & & \\
\hline Chloroform & 17.8 & 3.1 & 5.7 & 18.9 & 3.7 & $8.7^{\mathrm{a}}$ & & & \\
\hline Acetone & 15.5 & 10.4 & 7.0 & 19.9 & - & - & & & \\
\hline Water & 15.5 & 16.0 & 42.3 & 47.8 & - & - & & & \\
\hline $\begin{array}{c}\text { Acetone/water } \\
(70 / 30)\end{array}$ & 15.5 & 12.1 & 17.6 & 26.4 & - & $15.6^{\mathrm{b}}$ & & & \\
\hline PVP & 17.4 & 8.8 & 14.9 & 24.5 & & & $10.85^{\mathrm{b}}$ & - & 5.71 \\
\hline PEG400 & 19.18 & 3.49 & 3.58 & 19.8 & & & $3.5^{\mathrm{b}}$ & $10.65^{\mathrm{a}}$ & 18.02 \\
\hline PEO & 17.8 & 0.56 & 9.1 & 19.9 & & & $4.1^{\mathrm{b}}$ & $11.06^{\mathrm{a}}$ & 15.05 \\
\hline Span 80 & 17.2 & 7.7 & 10.3 & 21.5 & & & $6.6^{\mathrm{b}}$ & $5.5^{\mathrm{a}}$ & - \\
\hline
\end{tabular}

13 P: polymer, S: solvent, NS: non-solvent, A: additive; $\mathrm{NS}_{\mathrm{m}}$ : mixed non-solvent (acetone/water)

14 a Acetone as non-solvent (NS)

$15{ }^{\mathrm{b}}$ Chloroform as solvent (S) 

in order to select the adequate polymer to prepare porous membranes. COC is a copolymer of

4 ethylene and norbornene whereas COP is a polymer composed of only norbornene monomer. First,

5 COC was dissolved in TCB as it is explained previously and the resultant membrane (COC-TCB-

6 NA-A) was tested in DCMD short-term set-up using distilled water as feed at $70^{\circ} \mathrm{C}$ maintaining

7 the permeate temperature at $25^{\circ} \mathrm{C}$. No permeate flux was detected. The FESEM image of the cross-

8 section of this membrane (Fig. 5) showed that a thick dense layer was formed on the top of the

9 membrane surface. This may be related to polyethylene, which is present in the backbone chain.

10 So, TIPS method is required for the preparation of a completely porous structure from COC similar

11 to the preparation of porous polyethylene membrane. Based on this observation, COP was selected

12 for further studies as it is shown later on.

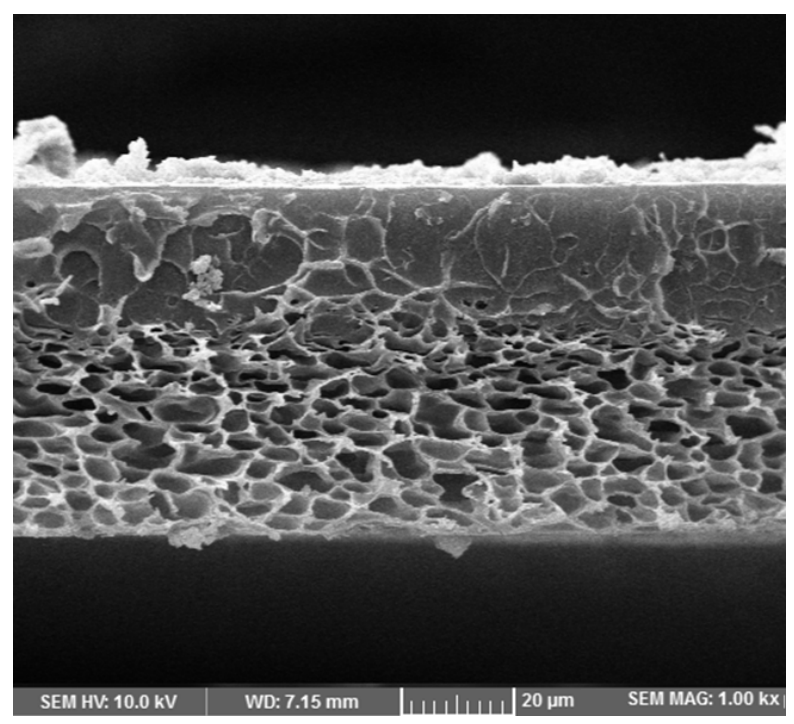


2

The COP membranes (TCB-NA-A and CF-NA-A, Table 3) were prepared using two different solvents, CF, which has more affinity to COP and TCB, which exhibits less affinity to COP (Table 4). Acetone was used as a non-solvent to prepare both membranes. No DCMD permeate flux could be detected for TCB-NA-A when using distilled water as feed and a bulk temperature difference of $45^{\circ} \mathrm{C}$. However, CF-NA-A shows a permeate flux of $20 \mathrm{~kg} \cdot \mathrm{m}^{-2} \mathrm{~h}^{-1}$ when distilled water was used as feed (Table 7). According to the cross section FESEM images of TCB-NA-A and CF-NA-A presented in Fig. 6, the structure of TCB-NA-A is uniformly spongy consisting of many small closed cells and a top dense skin layer, whereas the membrane CF-NA-A exhibits the characteristics of an asymmetric phase inversion membrane structure, consisting of a thick fingerlike structure, a top denser skin layer and a sponge-like bottom layer. The presence of the top dense layer of the membrane TCB-NA-A prevented water production by DCMD. It is worth noting that $R_{\text {SHP }}$ related to NS-S interaction for TCB-NA-A is higher than that of CF-NA-A. The low affinity between the non-solvent and solvent for TCB-NA-A resulted in slower inter-diffusion between them, a delayed COP coagulation and a sponge-like structure as a consequence. In general, during polymer solidification, the composition near the top surface of the membrane shifts to the polymerrich phase resulting in a denser top layer than that of the bottom. The opposite occurred for CFNA-A membrane resulting in a finger-like structure formation. The effect of solvent evaporation on membrane structure was investigated by Yamasaki et al. who claimed that more solvent evaporation time resulted in a thicker skin layer and more uniform structure [32]. Moreover, Friedrich et al. [33] investigated the effect of different solvents viscosity on the membrane structure and reported that the lower the solution viscosity resulted in a higher occurrence of cavities through the membrane. Therefore, in comparison to TCB, CF having lower viscosity and 
1 more affinity to polymer for better solubility and to coagulant (i.e. acetone) for higher exchange

2 rate of solvent and non-solvent was selected as solvent for next studies.

Both COC and COP are polyolefins. As mentioned in the previous section, COC containing

4 polyethylene in its backbone chain requires TIPS method for the preparation of a completely porous structure while COP acquires the characteristics of polyolefin and therefore it is possible to produce COP porous structure by NIPS method (CF or TCB-NA-A).
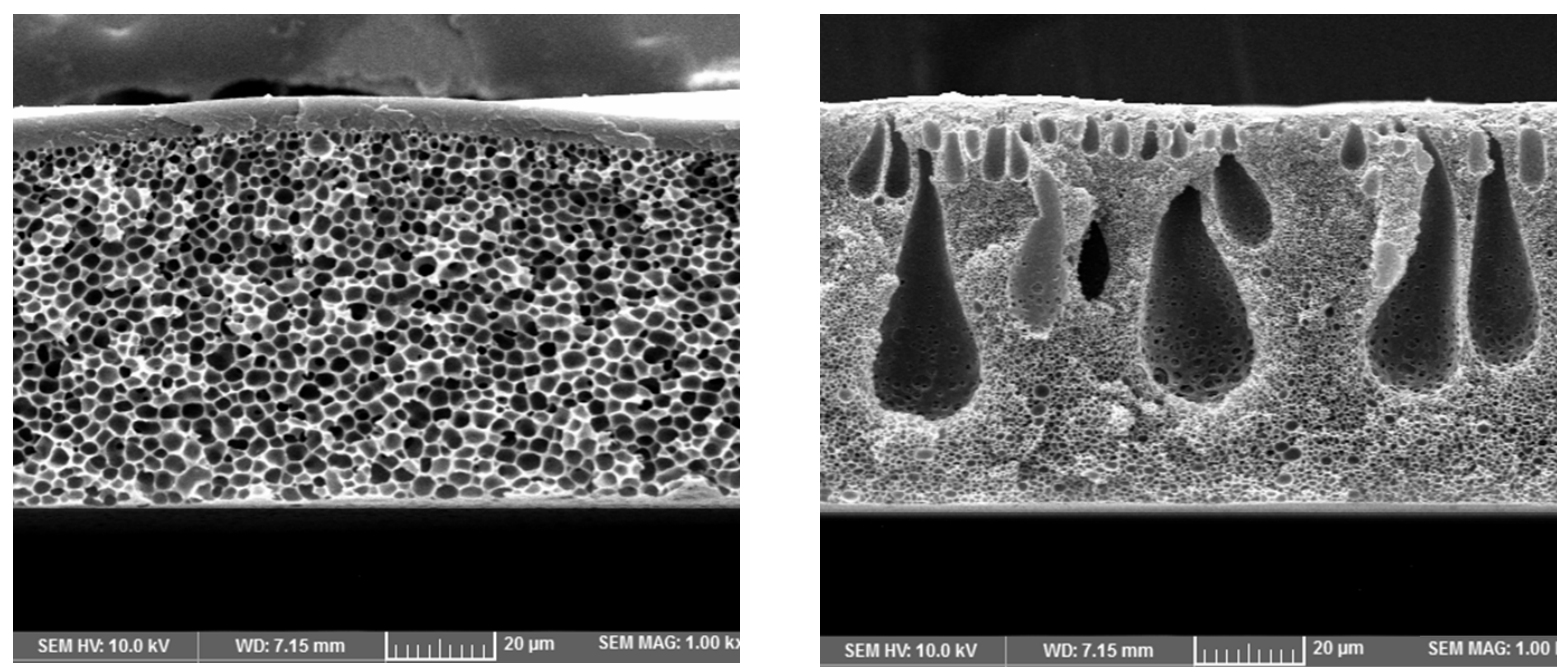

Fig. 6. Cross section FESEM image of TCB-NA-A (left) and CF-NA-A (right) membranes.

\subsection{Effect of PVP concentration on COP membrane structure and DCMD performance}

To study the effect of the additive concentration on the membrane structure, three COP

membranes (PVP-0.1, 0.2, 0.3-AW) were prepared with different amounts of PVP (0.1, 0.2 and

$0.3 \mathrm{wt} \%)$. Being a hydrophilic polymer, PVP is a well-known pore former used to prepare polymeric phase inversion porous membranes. Fig. 7 shows the FESEM images of the top, bottom and cross section of the PVP- 0.1, 0.2, 0.3-AW membranes. The three membranes exhibit a porous top layer, a finger-like structure (PVP-0.1-AW, PVP-0.2-AW) or macrovoids (PVP-0.3-AW) cross-section and a spongy bottom layer. These observations can be explained by means of the 
1 concept of phase separation rate, which is influenced by the complex correlation between the

2 thermodynamic enhancement and rheological hindrance inducing or suppressing the formation of

3 macrovoids or finger-like structure [34]. The addition of PVP into the polymer solution brought

4 an enhancement of demixing as a result of thermodynamic instability resulting in void or finger-

5 like structure formation. On the other hand, the effect of PVP on COP membrane structure may be

6 also explained using Hansen solubility parameter. The $R_{H S P}$ values for different additives-

7 solvent/non-solvents were determined and the obtained results were also listed in Table 4.

8 According to the obtained data, the affinity of PVP-acetone/water mixture is more than the affinity

9 of PVP-CF and consequently resulted in the rapid outflow of PVP and caused finger like structure.

10 However, the increase of PVP content in the casting solution (PVP-0.3-AW) caused an

11 enhancement of the viscosity and reduced the rate of solvent-non solvent exchange or which is the

12 same a delay of demixing. In this case, the predominant kinetic effect of the viscosity enhancement

13 might contribute to the suppression of the finger-like structure, an enhancement of the top skin

14 layer and the formation of macrovoids between the top and the spongy bottom layer. This was also

15 observed by Jung et al. [35] who found that the top membrane skin layer became thicker and the

16 finger like macrovoids disappeared with the increase of PVP concentration in the polymer solution

17 and this effect was more obvious in the case of high molecular weight of PVP because of its low

18 solubility in water. It seems that more amount of high molecular weight of PVP (i.e. PVP-0.3-

19 AW) caused macrovoids rather than PVP-0.1-AW and PVP-0.2-AW. It may also have suggested

20 that more PVP are located at PVP-0.3-AW membrane and could take a room in the pores [35]. 


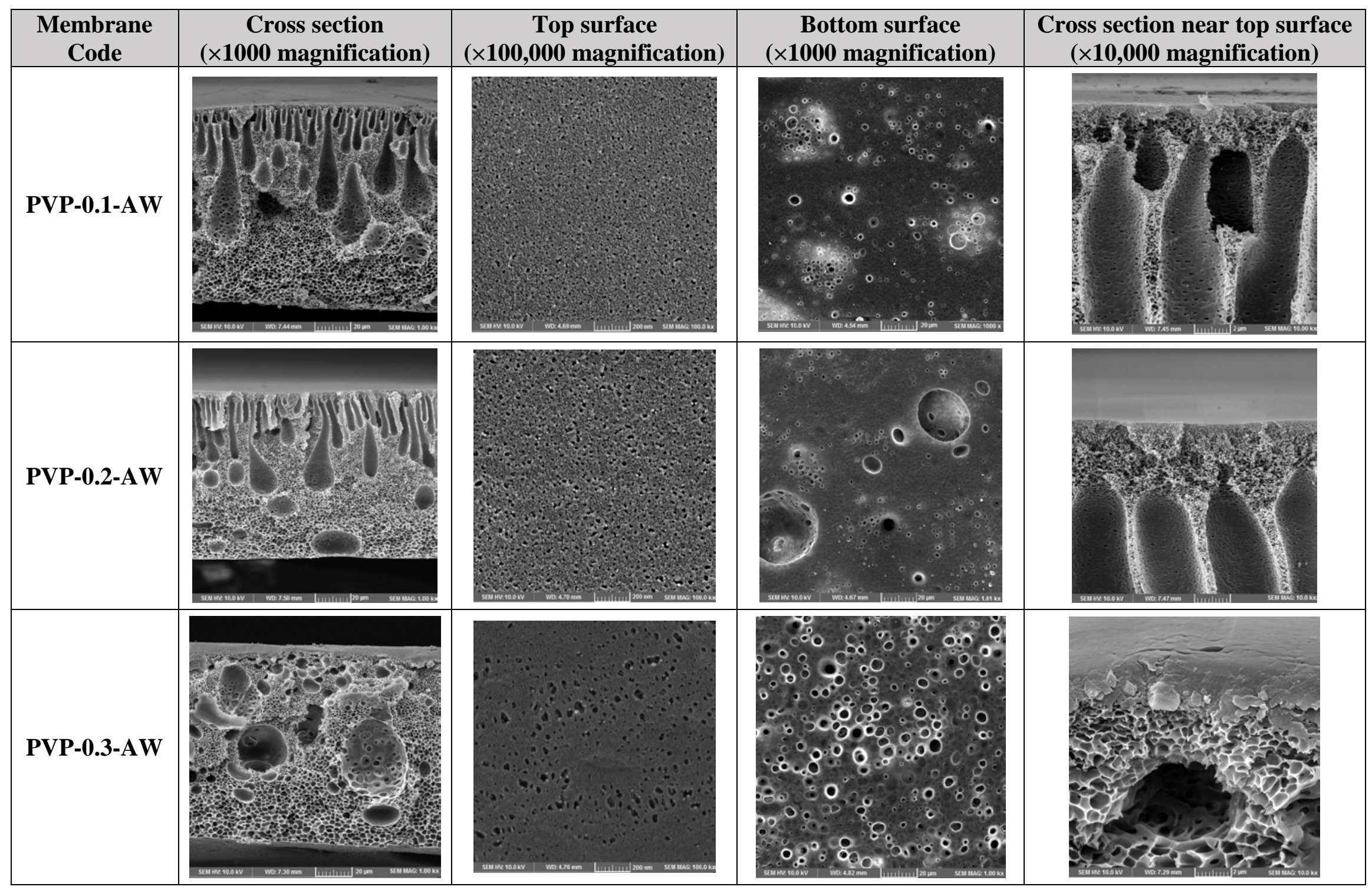

Fig. 7. FESEM images (cross section, top and bottom surfaces, and details of the cross section near the top surface) of the membranes prepared with different PVP concentrations (0.1-0.3 wt\%): PVP-0.1-AW, PVP-0.2-AW and PVP-0.3-AW. 
Table 5 summarizes the structural properties of all COP membranes prepared using chloroform as solvent in this study. The COP membrane without any additive (CF-NA-A) as well as the COP membranes prepared with PVP as additive showed a good porosity with values greater than $74.8 \%$. It is worth quoting that the high rate of demixing is, the greater porosity is achieved [36]. El-Bourawi et al. [8] reported that the porosity of MD membranes lies in the range of 30-85\%. Therefore, from the porosity point of view, all prepared membranes in this study are suitable for MD membranes.

The thickness, $L E P$, contact angle and mean pore size of COP membranes are also listed in Table 5. No significant difference could be drawn from the thickness of the membranes if the corresponding standard deviations are taken into consideration. The porosity of the membranes increased while the LEP and contact angle decreased when a larger amount of PVP was used as additive (PVP-0.1, 0.2, 0.3-AW in Table 5). The mean pore size was increased with the increase of the PVP concentration followed by a clear reduction. This decrease of the pore size may be due to the increase of the dense skin layer as it can be seen from the top surface of PVP-0.3-AW membrane (Fig. 7).

The membrane CF-NA-A prepared without any additive exhibits the highest water contact angle, $111^{\circ}$, showing the good hydrophobic character of COP material. All membranes, except PVP-0.3-AW, have a water contact angle greater than $90^{\circ}$ confirming their hydrophobicity. As it was expected, the addition of the hydrophilic additive PVP resulted in a decrease of the water contact angle (see CF-NAA and PVP-0.1, 0.2, 0.3-AW membranes in Table 5).

Although MD process is carried out under hydrostatic pressures near atmospheric pressure to guarantee an adequate membrane packing in modules and their subsequent stable long-term operation, the membrane must exhibit appropriate mechanical properties. The obtained stress-strain curves of the prepared COP membranes were plotted in Fig. 8. The tensile strength $\left(\sigma_{b}\right)$, elongation at break $\left(\varepsilon_{b}\right)$ and Young's modulus (E) were calculated and the results were given in Table 5. 
Table 5. Thickness, porosity $(\varepsilon)$, LEP, water contact angle $(\theta)$, mean pore size and mechanical properties (tensile strength, $\sigma_{b}$,

2 elongation at break, $\varepsilon_{b}$, and Young's modulus, E) of the prepared COP membranes.

\begin{tabular}{ccccccccc}
$\begin{array}{c}\text { Membrane } \\
\text { code }\end{array}$ & $\begin{array}{c}\text { Thickness } \\
(\boldsymbol{\mu m})\end{array}$ & $\boldsymbol{\varepsilon}(\mathbf{\%})$ & $\boldsymbol{L E P}(\mathbf{b a r})$ & $\boldsymbol{\theta}\left(\mathbf{}^{\circ}\right)$ & $\begin{array}{c}\text { Mean pore } \\
\text { size }(\mathbf{n m})\end{array}$ & $\sigma_{b}(\mathbf{M P a})$ & $\varepsilon_{b}(\mathbf{\%})$ & $\boldsymbol{E}(\mathbf{M P a})$ \\
\hline CF-NA-A & $85 \pm 5$ & $80.3 \pm 3.3$ & $1.96 \pm 0.19$ & $111.0 \pm 3.2$ & $211 \pm 3$ & $4.53 \pm 0.02$ & $4.1 \pm 1.4$ & $208 \pm 6$ \\
PVP-0.1-AW & $75 \pm 5$ & $74.8 \pm 1.5$ & $2.65 \pm 0.12$ & $92.1 \pm 1.7$ & $201 \pm 5$ & $4.67 \pm 0.36$ & $3.3 \pm 1.7$ & $215 \pm 5$ \\
PVP-0.2-AW & $70 \pm 5$ & $79.4 \pm 1.5$ & $1.67 \pm 0.18$ & $93.5 \pm 2.6$ & $265 \pm 6$ & $4.73 \pm 0.32$ & $6.8 \pm 1.7$ & $190 \pm 4$ \\
PVP-0.3-AW & $75 \pm 5$ & $82.3 \pm 1.3$ & $1.16 \pm 0.32$ & $86.3 \pm 1.5$ & $205 \pm 2$ & $5.51 \pm 0.39$ & $4.5 \pm 1.2$ & $237 \pm 9$ \\
PEG-0.2-A & $75 \pm 5$ & $75.8 \pm 1.8$ & $2.82 \pm 0.09$ & $102.9 \pm 2.4$ & $196 \pm 8$ & $4.82 \pm 0.19$ & $5.4 \pm 1.8$ & $210 \pm 7$ \\
PEG-0.2-AW & $75 \pm 5$ & $73.3 \pm 2.2$ & $2.04 \pm 0.14$ & $103.8 \pm 1.4$ & $158 \pm 5$ & $5.05 \pm 0.04$ & $6.1 \pm 1.8$ & $222 \pm 6$ \\
PEO-0.2-A & $80 \pm 5$ & $69.5 \pm 2.9$ & $3.10 \pm 0.26$ & $98.8 \pm 1.2$ & $254 \pm 12$ & $4.19 \pm 0.03$ & $3.5 \pm 0.4$ & $204 \pm 6$ \\
PEO-0.2-AW & $75 \pm 5$ & $61.3 \pm 1.6$ & $2.75 \pm 0.19$ & $99.7 \pm 2.7$ & $241 \pm 9$ & $0.74 \pm 0.04$ & $4.2 \pm 1.7$ & $29 \pm 1$ \\
Span 80-0.2-A & $80 \pm 5$ & $50.0 \pm 1.7$ & $4.55 \pm 0.34$ & $100.0 \pm 2.2$ & $239 \pm 2$ & $5.15 \pm 0.29$ & $7.9 \pm 1.0$ & $232 \pm 5$ \\
\hline
\end{tabular}


As can be seen in Fig. 8, all samples showed an elastic deformation at the beginning of the

2 stress-strain curve followed by a plastic deformation. By increasing the amount of PVP, the tensile strength of the membrane gradually increased up to $5.51 \mathrm{MPa}$ for the membrane PVP-0.3-AW while the elongation at break reached the optimum value of $6.76 \%$ for the membrane PVP-0.2AW and then decreased. This reduction may be attributed to the increase of the porosity of the membrane PVP-0.3-AW and the formed macrovoids through its cross-section (Fig. 7). Also, the Young's modulus for PVP modified membrane represents the minimum value of $190 \mathrm{MPa}$ for the membrane PVP-0.2-AW, due to its large finger-like structure. Moreover, the thick skin layer of the membrane PVP-0.3-AW may be responsible for its maximum E value. Simone et al. [37] investigated the effect of different amounts of PVP on the mechanical properties of hollow fiber PVDF membrane. They reported that by increasing the PVP content, the Young's modulus increased and then dropped off and further increment of PVP improved the mechanical strength. Alayande et al. [38] observed a higher porosity and a lower tensile strength with the addition of PVP to the dope solution. In general, compared to other MD membranes, all prepared COP membranes showed reasonably good mechanical properties. Tomaszewska [39] reported a strength at break of 1.6 MPa for a PVDF membrane that was decreased with the addition of $\mathrm{LiCl}$ due to macrovoid formation. Hou et al. also reported the stress at break for hollow fiber PVDF membrane of 4.66 MPa and elastic modulus of $160 \mathrm{MPa}$ [40]. However, compared to these membranes, the prepared COP membranes exhibited less elongation at break. This is related mainly to the plastic behavior of COP and its application under $T_{g}$ resulting in more brittle membranes. 


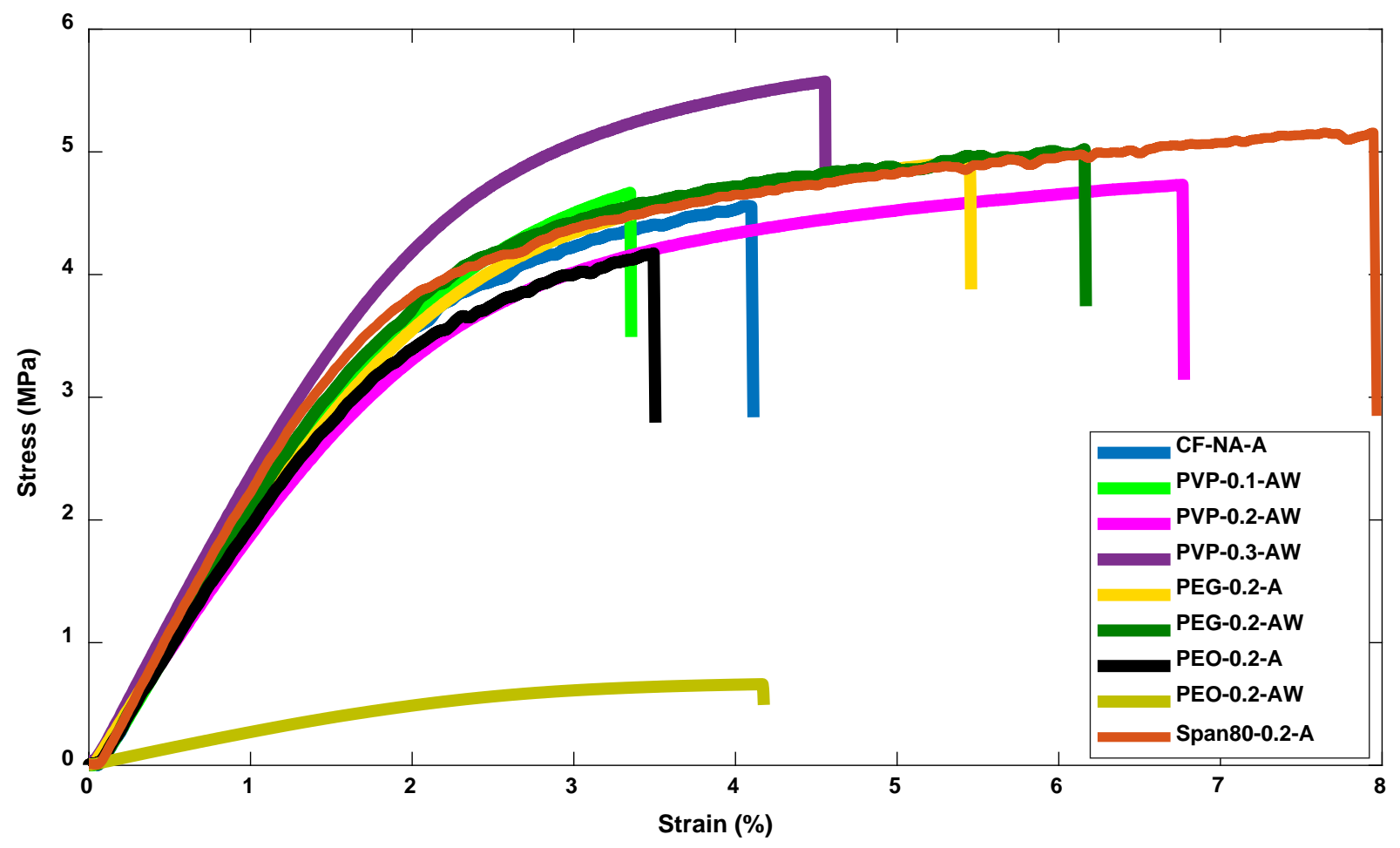

1

Fig. 8. Stress-strain curves of the prepared COP membranes.

Fig. 9 and Table 6 show the 3D AFM images and roughness parameters $\left(R_{a}\right.$ and $\left.R_{q}\right)$ of both the top and bottom surfaces of all COP membranes prepared with chloroform as solvent. All AFM images exhibited smooth nodule-like and valley-like structures. When the content of the PVP was increased (PVP-0.1, 0.2, 0.3-AW) inhomogeneous roughness was observed with some deep valleys and high peaks in some parts of the top membrane surface. The determined roughness parameters were higher for the membranes prepared with greater PVP amount. With the increase of PVP from $0.1 \mathrm{wt} \%$ to $0.2 \mathrm{wt} \%$, the roughness parameters and contact angles were maintained almost the same taking into consideration the corresponding standard deviations. It seems that the roughness increase counteracts the hydrophilic characteristic of PVP. A significant increase of $R_{a}$ and $R_{q}$ values was observed when the PVP content was increased from $0.2 \mathrm{wt} \%$ to $0.3 \mathrm{wt} \%$ for both the top ( $47 \%$ and $44 \%$, respectively) and bottom (56\% and $66 \%$, respectively) surfaces. However, $\theta$ values were decreased from $93.5^{\circ}$ to $86.3^{\circ}$ due to the hydrophilic character of PVP, 
1 which overcomes the effect of the roughness increase. It is worth mentioning that PVP-modified

2 membranes contain smooth surface along with intensified asperities in some parts of the membrane

3 surface (Fig. 9). In addition, the roughness parameters of the bottom surface are greater than the

4 top surface. This is due to the sponge-like structure of the bottom surface caused by the slower

5 phase inversion near the polymer/glass interface compared to the air/polymer interface [41].

7 Table 6. Roughness parameters $\left(R_{a}, R_{q}\right)$ together with the corresponding standard deviations of 8 the top and bottom surfaces of the prepared COP membranes (scan range considered $5 \mu \mathrm{m} \times 5 \mu \mathrm{m}$ ).

\begin{tabular}{cccccc}
\hline \multirow{2}{*}{ Membrane code } & \multicolumn{2}{c}{ Top surface } & & \multicolumn{2}{c}{ Bottom surface } \\
\cline { 2 - 3 } \cline { 5 - 6 } & $\boldsymbol{R}_{\boldsymbol{a}}(\mathbf{n m})$ & $\boldsymbol{R}_{\boldsymbol{q}}(\mathbf{n m})$ & & $\boldsymbol{R}_{\boldsymbol{a}}(\mathbf{n m})$ & $\boldsymbol{R}_{\boldsymbol{q}}(\mathbf{n m})$ \\
\hline CF-NA-A & $106.4 \pm 3.8$ & $126.7 \pm 5.0$ & & $108.1 \pm 0.5$ & $132.1 \pm 4.0$ \\
PVP-0.1-AW & $99.6 \pm 6.0$ & $129.2 \pm 18.1$ & & $225.4 \pm 2.1$ & $265.2 \pm 7.3$ \\
PVP-0.2-AW & $105.9 \pm 10.0$ & $131.4 \pm 18.9$ & & $237.5 \pm 7.2$ & $258.4 \pm 5.2$ \\
PVP-0.3-AW & $155.6 \pm 12.0$ & $189.6 \pm 18.2$ & & $369.7 \pm 20.1$ & $428.2 \pm 18.5$ \\
PEG-0.2-A & $81.4 \pm 2.0$ & $94.7 \pm 2.5$ & & $237.2 \pm 2.4$ & $278.0 \pm 5.3$ \\
PEG-0.2-AW & $99.8 \pm 14.0$ & $116.7 \pm 12.7$ & & $248.8 \pm 11.2$ & $298.3 \pm 17.5$ \\
PEO-0.2-A & $99.0 \pm 16.5$ & $121.9 \pm 15.8$ & & $212.5 \pm 5.6$ & $253.9 \pm 18.3$ \\
PEO-0.2-AW & $131.6 \pm 2.0$ & $159.2 \pm 2.2$ & & $236.3 \pm 6.4$ & $290.1 \pm 15.6$ \\
Span 80-0.2-A & $107.9 \pm 2.8$ & $129.3 \pm 4.8$ & & $120.3 \pm 3.6$ & $152.3 \pm 6.5$ \\
\hline
\end{tabular}

The obtained short-term DCMD results are shown in Table 7. No clear trend could be plotted 11 between the permeate flux and the PVP concentration in the COP solution. With the increase of 12 the PVP concentration from 0.1 to $0.2 \mathrm{wt} \%$, the permeate flux was increased and with a further 13 increase of PVP concentration up to $0.3 \mathrm{wt} \%$ it was decreased. This can be related with the pore 
1 size as it was discussed before (Table 5). Moreover, the surface roughness affects the MD

2 performance so that the higher surface roughness, the lower temperature and concentration

3 polarization (TCP). The enhancement of the surface roughness might contribute to the reduction

4 of the TCP effect attributed to the generated micro-turbulences at the membrane surface and might

5 increase the DCMD permeate flux. Compared to the membrane PVP-0.1-AW, some improvement

6 in roughness parameters of the membrane PVP-0.2-AW resulted in a little enhancement of the

7 water contact angle. Therefore, this effect together with the increase of the mean pore size resulted

8 in some improvements of the permeate flux (Table 7). However, the high $R_{a}$ value of the membrane

9 PVP-0.3-AW was not related to the DCMD permeate flux improvement (Table 7) because the

10 mean pore size dropped from $265 \mathrm{~nm}$ to $205 \mathrm{~nm}$ (see Table 5). The slight decline of the salt

11 separation factor observed for the PVP-0.3-AW membrane can be due to the reduction of the $L E P$

12 (Table 5). All PVP-0.3-AW membrane results seem to indicate that an increase of the PVP content

13 from 0.2 to 0.3 wt.\% reduced the MD performance because bigger macrovoids appeared through

14 its cross-section (see Fig. 7) and these are well-known by their reduction of the permeate flux.

15 It is worth noting that the highest permeate flux in short-term DCMD was obtained for the 16 membrane CF-NA-A with a high salt separation factor (99.99\%). However, it is essential to track 17 its performance in long-term DCMD, too. Among all prepared COP membranes with additives, 18 PVP-0.2-AW membrane exhibited the highest short-term DCMD performance. Based on these 19 DCMD results, in order to compare the effect of different types of additives on the COP membrane 20 structure and DCMD performance, the amount of all additives was fixed at $0.2 \mathrm{wt} \%$. 


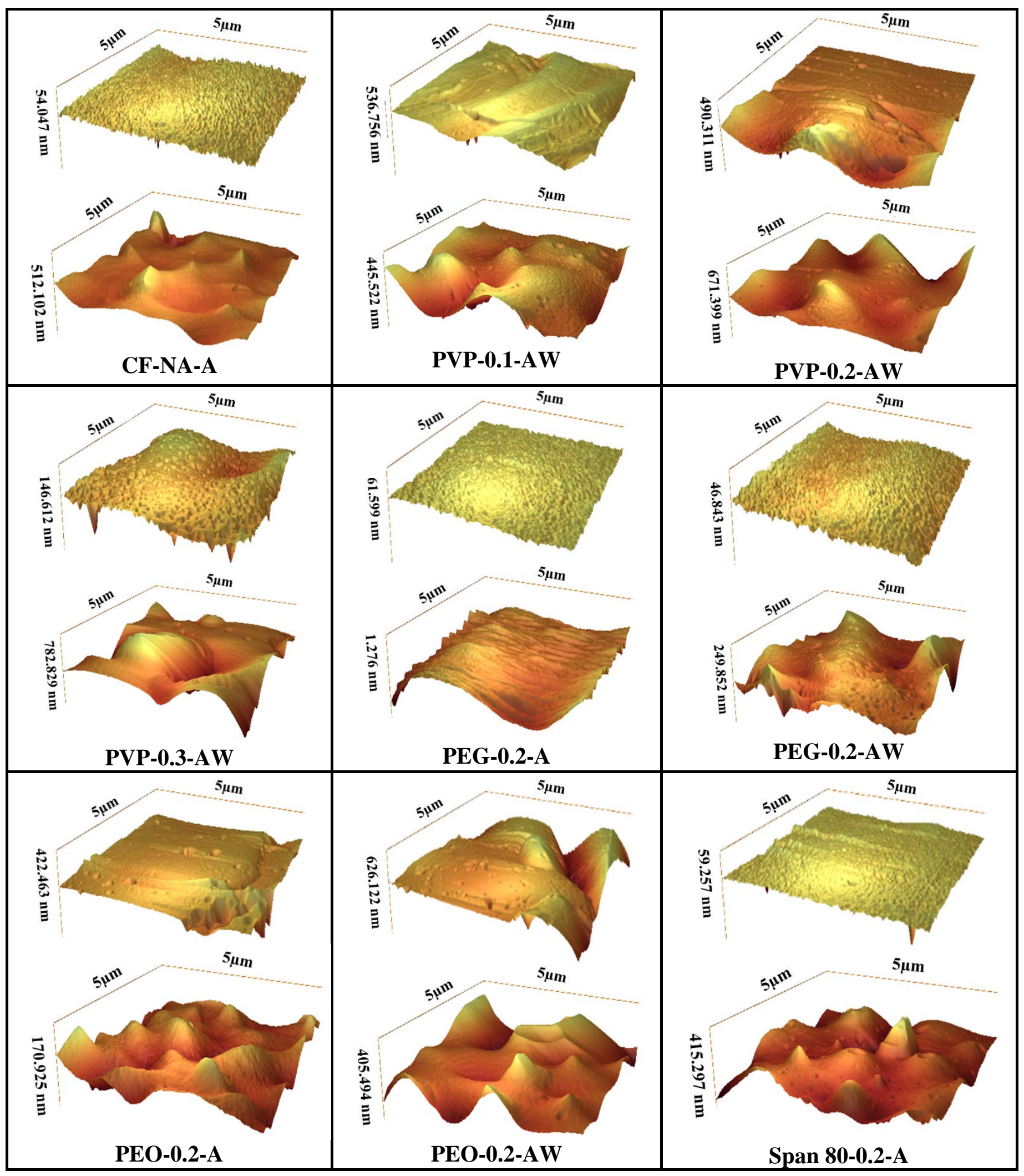

1 Fig. 9. 3D AFM images of the top (up) and bottom (down) surfaces of the prepared COP 2 membranes. 
1 Table 7. Short-term DCMD performance.

\begin{tabular}{|c|c|c|c|c|c|c|c|c|c|}
\hline \multirow{2}{*}{$\begin{array}{l}\text { Membrane } \\
\text { code }\end{array}$} & \multirow{2}{*}{$\begin{array}{c}\text { Distilled water } \\
\text { flux }\left(J_{w}\right) \\
\left(\mathbf{k g} / \mathbf{m}^{2} \mathbf{h}\right)\end{array}$} & \multirow{2}{*}{$\begin{array}{l}\text { Permeate flux }(J) \\
\qquad\left(\mathbf{k g} / \mathbf{m}^{2} \mathbf{h}\right)\end{array}$} & \multicolumn{3}{|c|}{$\begin{array}{l}\text { Electrical conductivity of permeate } \\
\qquad(\mu \mathrm{S} / \mathrm{cm})\end{array}$} & \multicolumn{3}{|c|}{$\begin{array}{l}\text { Electrical conductivity of feed } \\
\qquad(\mathrm{mS} / \mathrm{cm})\end{array}$} & \multirow{2}{*}{$\begin{array}{l}\text { Salt separation } \\
\text { factor }(\alpha)(\%)\end{array}$} \\
\hline & & & Test 1 & Test 2 & Test 3 & Test 1 & Test 2 & Test 3 & \\
\hline CF-NA-A & $20.0 \pm 0.5$ & $15.0 \pm 1.0$ & $4.726 \pm 0.002$ & $5.103 \pm 0.001$ & $5.241 \pm 0.001$ & $46.63 \pm 0.02$ & $46.55 \pm 0.03$ & $46.72 \pm 0.02$ & $99.9942 \pm 0.0004$ \\
\hline PVP-0.1-AW & $11.0 \pm 0.7$ & $9.0 \pm 0.9$ & $4.361 \pm 0.001$ & $3.988 \pm 0.002$ & $4.232 \pm 0.001$ & $46.78 \pm 0.02$ & $47.08 \pm 0.03$ & $46.98 \pm 0.04$ & $99.9955 \pm 0.0006$ \\
\hline PVP-0.2-AW & $16.0 \pm 1.0$ & $13.0 \pm 1.3$ & $5.553 \pm 0.002$ & $5.932 \pm 0.001$ & $6.141 \pm 0.003$ & $46.54 \pm 0.01$ & $46.49 \pm 0.02$ & $46.51 \pm 0.02$ & $99.9928 \pm 0.0005$ \\
\hline PVP-0.3-AW & $8.4 \pm 1.2$ & $7.4 \pm 1.4$ & $10.92 \pm 0.002$ & $11.68 \pm 0.002$ & $12.011 \pm 0.001$ & $46.50 \pm 0.01$ & $46.35 \pm 0.02$ & $46.43 \pm 0.01$ & $99.9837 \pm 0.0006$ \\
\hline PEG-0.2-A & $14.0 \pm 1.0$ & $12.3 \pm 1.1$ & $2.796 \pm 0.002$ & $3.315 \pm 0.002$ & $3.535 \pm 0.002$ & $47.45 \pm 0.02$ & $47.13 \pm 0.02$ & $47.23 \pm 0.02$ & $99.9972 \pm 0.0006$ \\
\hline PEG-0.2-AW & $11.0 \pm 0.8$ & $8.0 \pm 1.0$ & $9.578 \pm 0.001$ & $10.257 \pm 0.001$ & $10.860 \pm 0.002$ & $46.51 \pm 0.02$ & $46.36 \pm 0.02$ & $46.47 \pm 0.01$ & $99.9858 \pm 0.0010$ \\
\hline PEO-0.2-A & $9.0 \pm 1.1$ & $7.3 \pm 0.9$ & $3.411 \pm 0.004$ & $3.107 \pm 0.003$ & $3.732 \pm 0.002$ & $46.92 \pm 0.02$ & $47.17 \pm 0.01$ & $46.89 \pm 0.01$ & $99.9968 \pm 0.0005$ \\
\hline PEO-0.2-AW & $3.1 \pm 0.8$ & $2.2 \pm 0.6$ & $13.562 \pm 0.001$ & $12.841 \pm 0.002$ & $14.215 \pm 0.001$ & $46.39 \pm 0.02$ & $46.41 \pm 0.02$ & $46.30 \pm 0.01$ & $99.9805 \pm 0.0011$ \\
\hline Span 80-0.2-A & $5.3 \pm 1.6$ & $3.0 \pm 0.8$ & $2.882 \pm 0.001$ & $2.109 \pm 0.002$ & $1.899 \pm 0.001$ & $46.88 \pm 0.01$ & $46.68 \pm 0.02$ & $47.12 \pm 0.01$ & $99.9986 \pm 0.0008$ \\
\hline
\end{tabular}


The characteristics and DCMD performance of the prepared porous COP membranes were also summarized in Tables 5 and 7, respectively. First, the effects of the additives on the membrane

4 morphology, structural properties and DCMD performance are discussed, then the effects of the coagulants on the same membrane properties.

7 performance

For porous membrane preparation, PVP, PEG and PEO are commonly used as relatively 9 hydrophilic additives. Span 80 was used as a non-ionic surfactant with hydrophile-lipophile value (HLB) of 4.3 in polymer solutions [42]. It was claimed that the addition of PEGs commonly

11 inhibits macrovoids formation, improves pores interconnectivity and increases the membrane 12 porosity [43]. This was proved in this study as can be seen in Fig. 10 for the membrane PEG-0.2-

13 A. The addition of PEG400 resulted in an effective transformation of finger-like and macrovoids 14 structure to more sponge-like or honey-comb structure. According to the $R_{H S P}$ value of PEG shown 15 in Table 4, the affinity of PEG-CF $\left(R_{H S P}=3.5\right)$ is better than that of PEG-acetone or acetone/water 16 mixture ( $R_{H S P}=10.65$ and 18.02, respectively). The less exchange rate of PEG with the coagulants 17 caused a slower outflow rate of PEG, slower inflow of non-solvent and therefore slower outflow of solvent during membrane formation inhibiting macrovoids formation as a consequence. As a 19 result, the porosity was decreased (PEG-0.2-A membrane in Fig. 10 and Table 5). Compared to 20 other membrane samples, using PEG400 as additive caused the reduction of the mean pore size 21 (196 nm for PEG-0.2-A vs. $211 \mathrm{~nm}$ and $265 \mathrm{~nm}$ for CF-NA-A and PVP-0.2-AW, respectively, 22 Table 5) and the enhancement of LEP (2.82 bar for PEG-0.2-A vs. 1.96 bar for CF-NA-A and 1.67 
1 bar for PVP-0.2-AW, respectively, Table 5). It is worth noting that the precipitation kinetic and

2 consequently the exchange rate of solvent and non-solvent were affected by the hydrophilic nature of PEG400. Kim and Lee [44] also reported that PEGs of small molecular weights, like PEG200

4 and PEG400, act as a pore-reducing agent in asymmetric polyetherimide (PEI) membranes.

As can be seen in Fig. 10, the finger-like structure of the CF-NA-A was transformed to the 6 sponge-like structure up on the addition of PEO. Both PEO and PEG have the same constitutional 7 units but with different synthesis methods, which results in a higher molecular weight for PEO.

8 Therefore, compared to PEG400, PEO has a slower dissolution rate in a solvent due to its higher 9 molecular weight resulting in a higher viscosity polymer solution. In this case, as it is mentioned earlier, because of the enhanced viscosity, the kinetic effect may become predominant over the

11 thermodynamic effect and the solvent/non-solvent interdiffusion is delayed. It was proposed that 12 under this delayed condition, the top layer has low porosity with low degree of pore 13 interconnectivity [45]. In addition, the suppression of macrovoids in the sublayer could also be 14 observed [46]. Thus, it may be expected a membrane with low porosity and permeability. As a 15 result, the porosity of the membrane PEO-0.2-A was lower than that of PEG-0.2-A membrane 16 (69.5\% and 75.8\%, respectively, Table 5). Gao et al. [47] also investigated the transition 17 morphology of Poly (L-lactic acid) (PLLA) flat sheet membrane from finger-like pores to inter18 connected pores by using PEO and PEG with different molecular weights. It was proved that the 19 increase of the molecular weight of polymer chain (i.e. using PEO instead of PEG), changed the 20 phase separation process to spinodal decomposition (SD) mechanism and the membrane structure 21 transformed from finger-like to inter-connected network by increasing the concentration (wt\%) of 22 PEO in the casting solution. In addition, the $R_{H S P}$ value of PEO-acetone is higher than that of PEG23 acetone (i.e. less affinity of PEO towards the non-solvent compared to PEG400, Table 4). In this 
1 regards, the less porosity and pore size of PEO-0.2-A compared to PEG-0.2-A is also justified.

2 The $R_{H S P}$ data related to PEO also showed less affinity of PEO with the non-solvents (both acetone

3 and acetone/water) and consequently less diffusion rate of PEO to the coagulants. The less

4 exchange rate of PEO with the coagulants caused a slower outflow rate of PEO and inflow rate of

5 the non-solvent during membrane formation inhibiting therefore macrovoids formation. In

6 contrast, the $R_{H S P}$ data related with PVP showed more affinity of PVP with the non-solvents rather

7 than with the solvent (Table 4). This resulted in an intense phase separation process between the

8 polymer-rich phase and the polymer-lean phase and consequently macrovoids formation. In fact,

9 the porosity and mean pore size of PVP-0.2-AW (79.4\% and $265 \mathrm{~nm}$, respectively, Table 5) are

10 greater than those of PEO-0.2-A and PEO-0.2-AW (69.5\%, 61.3\% and 254, $241 \mathrm{~nm}$, respectively, 11 Table 5). 


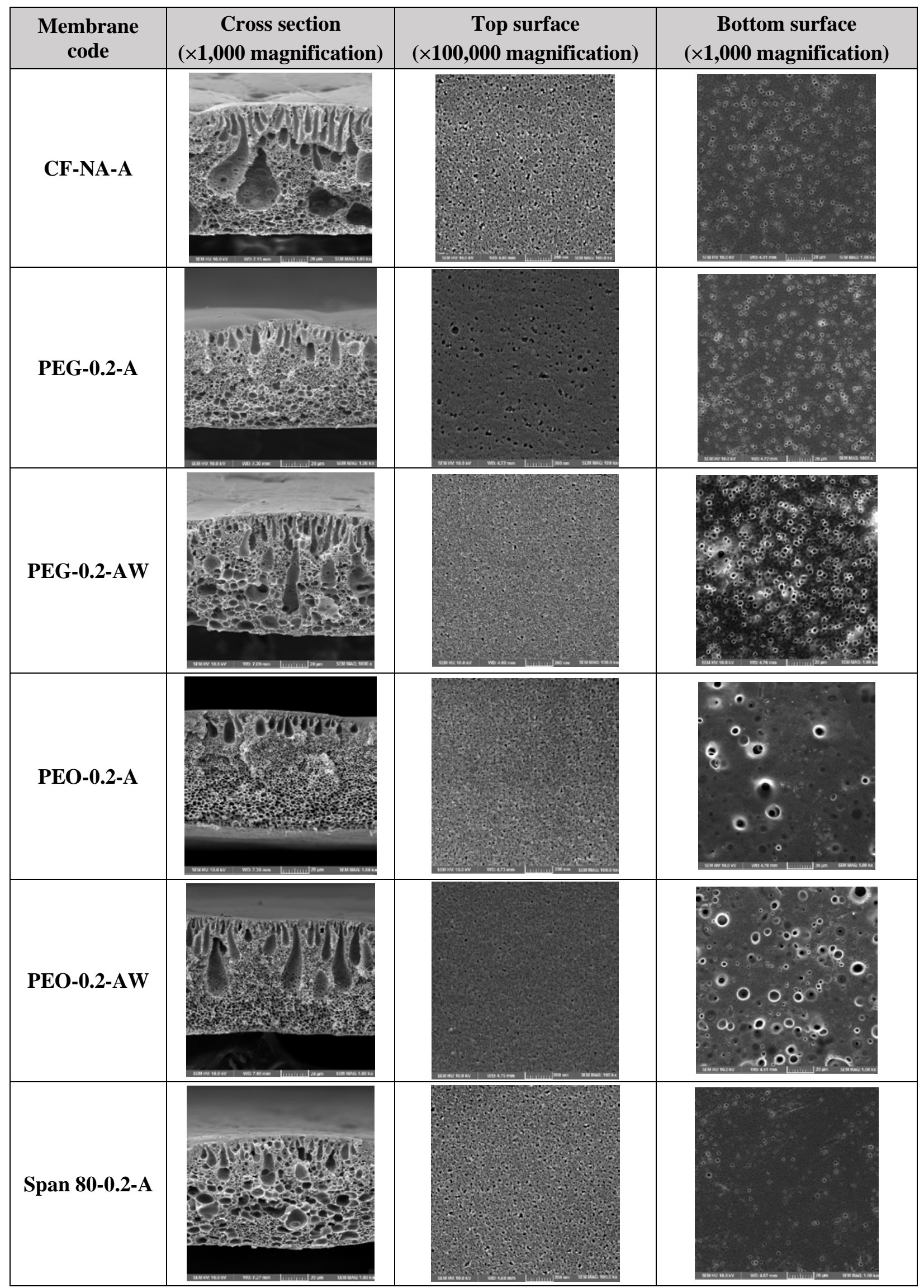

1 Fig. 10. FESEM images of COP membranes prepared by different types of additives. 
The additive Span 80 was selected to study COP phase separation because of its higher

hydrophobic character compared to the other used additives. It is worth mentioning that the affinity of a given surfactant to water or oil can be expressed by the HLB value, The less the HLB value, the more hydrophobicity of the surfactant. Moreover, the Span 80 is a nonionic surfactant according to the form of its dissociation in the solvent. Since the addition of a surfactant affects the interfacial properties between coagulant and polymer solution, the membrane structure might be drastically changed. The membrane Span 80-0.2-A exhibits elongated macrovoids through its cross section and small finger like macrovoids near the top surface. Ge et al. [48] concluded that the addition of low HLB surfactant to the casting solution slowed down the rate of phase separation and increases its stability. It was also observed an increase of macrovoids in the sublayer of polysulfone membranes sublayer with the increase of HLB value of the surfactants. Tsai et al. [42] investigated the effect of a wide variety of surfactants with different HLB's and concluded that for a hydrophilic coagulant, hydrophilic surfactant enhanced macrovoids formation and a lipophilic surfactant was more effective to change the structure of membrane when the coagulant was lipophilic. In the present case, the affinity of Span 80-coagulant $\left(R_{H S P}=5.5\right)$ and solvent $\left(R_{H S P}=6.6\right)$ is almost similar according to the $R_{H S P}$ values (Table 4). On the other hand, acetone is slightly lipophilic. As a result, the finger-like macrovoids of Span 80-0.2-A membrane was reduced and the spongy structure changed to big pores across the membrane. Consequently, the mean pore size of Span 80-0.2-A (239 nm) turned to be bigger than that of CF-NA-A, PEG-0.2-A and PEG-0.2AW (211,196, $158 \mathrm{~nm}$, respectively, Table 5) and smaller than that of PVP-0.2-AW, PEO-0.2-A and PEO-0.2-AW membranes (265, 254 and $241 \mathrm{~nm}$, respectively, Table 5).

The addition of both PEO and Span 80 reduced the membrane porosity (69.5\% and 50.0\% for PEO-0.2-A and Span 80-0.2-A, respectively, vs. 80.3\% for CF-NA-A) but increased the LEP value 
1 (3.1 bar and 4.55 bar for PEO-0.2-A and Span 80-0.2-A, respectively, vs. 1.96 bar for CF-NA-A).

2 This is attributed to the reduction of the bubble pore size. It was reported an enhancement of the

3 membrane porous structure as the considered polymer solution became easier to phase separate

4 [49]. Therefore, it is predictable the low porosity of the membranes PEO-0.2-A and Span 80-0.2-

5 A because of the slower polymer phase separation compared to the membranes CF-NA-A and

6 PVP-0.2-AW prepared with faster phase separation causing a finger-like structure.

7 As it is expected, the addition of a hydrophilic additive (PVP, PEG400 and PEO) may decrease

8 the water contact angle of COP membranes if not leached out totally during membrane formation.

9 The water contact angle was reduced in the order PEG-0.2-A > PEO-0.2-A > PVP-0.2-AW

10 indicating that the PEG400 additive affects less the membrane hydrophobic character than the PVP

11 additive. It must be pointed out that the addition of Span 80 also resulted in a decrease of the water

12 contact angle even more than that of PEG400 (102.9 for PEG-0.2-A with $100^{\circ}$ for PEO-0.2-A).

13 Span 80 has both hydrophilic and lipophilic segments and the hydrophilic part may be responsible

14 for the reduction of water contact angle. As it is mentioned before, the PEG400 additive is a small

15 molecule so it can be easily removed by the non-solvent.

16 The addition of PEG400 increased the tensile strength, elongation at break and Young's

17 modulus compared to CF-NA-A and PVP-0.2-Aw (Table 5) which may be due to the decrease of

18 the porosity and change of the morphology of the CF-NA-A and PVP-0.2-AW membranes from

19 finger-like structure to sponge-like structure with smaller macrovoids (see Table 5 and Fig. 10).

20 As it was discussed previously, the addition of PEG400 suppressed the macrovoids and reduced

21 the porosity (i.e. void volume fraction). Tsai et al. [50] also mentioned that cavities present in

22 membranes could induce stress centralization forming weak points under an applied force and

23 reduced mechanical properties. 
According to the data shown in Table 5, the addition of PEO has a negative effect on the mechanical properties. Although the membrane PEO-0.2-A has a sponge-like structure with almost little macrovoids and less porosity, its tensile strength was decreased compared to the membrane CF-NA-A. The membrane Span 80-0.2-A exhibited low porosity compared to all other COP membrane but showed the highest mechanical properties (5.15 MPa for tensile strength, 7.94\% elongation at break and $232 \mathrm{MPa}$ for Young's modulus). This is attributed to its low porosity provided that a higher porosity weakens the membrane strength.

The short-term DCMD performance of the prepared porous COP membranes (CF-NA-A, PVP0.2-AW, PEG-0.2-A, PEO-0.2-A and Span 80-0.2-A) was also summarized in Table 7. Based on the obtained results, the addition of PEG400 resulted in a slight decrease of the permeate flux compared to CF-NA-A and PVP-0.2-AW (Table 7) due to the decrease of its pore size and porosity (Table 5). Although the mean pore size of PEO-0.2-A is higher than that of PEG-0.2-A and CFNA-A (254 nm vs. $196 \mathrm{~nm}$ and $211 \mathrm{~nm}$, respectively, Table 5), an important decrease of the permeate flux was observed for PEO-0.2-A (see Table 7). As it is mentioned earlier, the addition of a high molecular weight PEO (i.e. membrane PEO-0.2-A) resulted in less porosity compared to PEG (i.e. membrane PEG-0.2-A) and a lower permeate flux. The lowest permeate flux was obtained for the membrane Span 80-0.2-A because of its lowest porosity (50\%) compared to the membranes CF-NA-A, PVP-0.2-AW, PEG-0.2-A and even PEO-0.2-A. It must be pointed out that the salt separation factor of the membranes CF-NA-A, PVP-0.2-AW, PEG-0.2-A, PEO-0.2-A and Span $80-0.2-$ A was above $99.99 \%$ and the detected slight lower value $99.98 \%$ for the membrane PVP-0.3-AW was due to its lower $L E P$ value (Table 5). 

performance

The effect of the coagulant on the morphological characteristics of two types of membranes

4 (PEG-0.2-A/ PEG-0.2-AW and PEO-0.2-A/PEO-0.2-AW) was also investigated. With the addition of water (30 wt $\%$ ) to acetone, the $R_{H S P}$ value of the additive-mixed non-solvents increased in relation with that of the additive-acetone (see Table 4) indicating less affinity of the additive to

7 the coagulant. As it is mentioned earlier, the slower outflow of the solvent caused suppression of macrovoids and consequently resulted in less porosity and smaller mean pore size. By comparing

9 the membranes PEG-0.2-AW with PEG-0.2-A and PEO-0.2-AW with PEO-0.2-A, the addition of water to acetone resulted in lower porosity and pore size (i.e. $73 \%, 158 \mathrm{~nm}$ and $61.3 \%$, 241nm for

11 PEG-0.2-AW and PEO-0.2-AW, respectively, Table 5) than those of the membranes PEG-0.2-A 12 and PEO-0.2-A, respectively (i.e. 75\%, $196 \mathrm{~nm}$ and 69.5\%, $254 \mathrm{~nm}$, respectively, Table 5).

13 Moreover, although the mean pore size of membranes prepared with acetone/water are less than 14 that of the membranes prepared with acetone, a little increase of the bubble pore size was observed 15 (Fig.10) and consequently resulted in a little decrease of LEP (Table 5).

16 Based on the obtained data of water contact angle of the membrane PEG-0.2-AW compared to 17 PEG-0.2-A (103.8 and 102.9 ${ }^{\circ}$, respectively, Table 5) and the membrane PEO-0.2-AW compared 18 to PEO-0.2-A (99.7 ${ }^{\circ}$ and $98.8^{\circ}$, respectively, Table 5), the addition of water to acetone led to a 19 slight increase of water contact angle may be due to the increase of the roughness parameters 20 (Table 6). Furthermore, the addition of water to acetone increased the tensile strength, the 21 elongation at break and Young's modulus of the membranes prepared with PEG as additive. In 22 contrast, the mechanical properties of the membrane prepared with PEO were lower (i.e. the tensile 23 strength of the membrane PEO-0.2-AW is $0.74 \mathrm{MPa}$ ) due to the fact that water intensified the 
1 phase separation of the polymer solution inducing interfacial pores between the PEO and COP

2 polymer.

3 The effect of the coagulant (acetone and acetone/water) on the DCMD performance was also

4 shown in Table 7. Compared to the membranes prepared in acetone, bigger macrovoids appeared

5 in the structure of the COP membranes prepared with PEG400 and PEO in the acetone-water

6 mixture (i.e. a slight increase of the bubble pore size and decrease of the $L E P$ ). Based on the data

7 shown in Table 7, the observed decrease of the permeate flux was due to the less porosity and pore

8 size while the decrease of the salt separation factor was due to the slight reduction of the LEP of

9 PEG, PEO-0.2-AW membranes compared to PEG, PEO-0.2-A membranes, respectively.

10 For sake of comparison, Table 8 lists the DCMD performance of some commercial and

11 prepared membranes together with their characteristics. It can be seen that COP membranes exhibit

12 DCMD permeate fluxes within those presented in Table 8. In fact, COP membranes showed

13 slightly lower permeate fluxes than some commercial PVDF membranes (GVHP and HVHP) and

14 PTFE membranes (TF200 and TF450), but higher than those of the commercial membranes (PE

15 and MCE) and comparable to that of the commercially available PVDF membrane (PVDF22). 
Table 8. Reported DCMD permeate flux $(J)$ of different types of commercial and prepared flat sheet membranes together with their characteristics $\left(\mu_{P}\right.$ : mean pore size; $T_{f}$ feed temperature; $T_{p}$ : permeate temperature).

\begin{tabular}{|c|c|c|c|c|c|c|c|c|}
\hline Membrane material & $\begin{array}{l}\text { Thickness } \\
(\mu \mathrm{m})\end{array}$ & $\underset{(\mu \mathrm{m})}{\mu_{P}}$ & $\begin{array}{l}L E P \\
\text { (bar) }\end{array}$ & $\varepsilon(\%)$ & $\begin{array}{c}\theta \\
\left({ }^{\circ}\right)\end{array}$ & $\begin{array}{c}J \\
\left(\mathrm{~kg} / \mathrm{m}^{2} \mathrm{~h}\right)\end{array}$ & Test conditions & Ref. \\
\hline $\mathrm{GVHP}^{\mathrm{a}}$ & 118 & 0.22 & 2 & 70.1 & 110 & $\begin{array}{l}32.4 \\
25.2\end{array}$ & $\begin{array}{l}\text { distilled water as feed; } T_{f}=70^{\circ} \mathrm{C} ; T_{p}=20^{\circ} \mathrm{C} \\
\text { distilled water as feed; } T_{f}=70^{\circ} \mathrm{C} ; T_{p}=20^{\circ} \mathrm{C}\end{array}$ & $\begin{array}{l}{[51]} \\
{[52]}\end{array}$ \\
\hline $\mathrm{HVHP}^{\mathrm{a}}$ & 116 & 0.45 & 1.1 & 71.3 & - & 38.8 & distilled water as feed; $T_{f}=70^{\circ} \mathrm{C} ; T_{p}=20^{\circ} \mathrm{C}$ & [51] \\
\hline PVDF22 $^{\mathrm{a}}$ & 125 & 0.22 & 2.17 & 75 & 127.2 & 25 & distilled water as feed; $T_{f}=80^{\circ} \mathrm{C} ; T_{p}=20^{\circ} \mathrm{C}$ & [53] \\
\hline $\mathrm{PE}^{\mathrm{b}}$ & 38 & 0.3 & $>3$ & 88 & 118 & $\sim 18$ & $\begin{array}{c}\text { distilled water as feed; } T_{f}=70^{\circ} \mathrm{C} ; T_{p}=30^{\circ} \mathrm{C} \\
\text { Feed flow rate; } 74 \mathrm{~L} / \mathrm{h}\end{array}$ & {$[54]$} \\
\hline TF200' & 0.178 & 0.2 & 0.282 & 80 & - & $\begin{array}{l}\sim 20 \\
\sim 25\end{array}$ & $\begin{array}{l}\text { Olive mill wastewater as feed; } T_{f}=70^{\circ} \mathrm{C} ; T_{p}=20^{\circ} \mathrm{C} \\
\text { distilled water as feed; } T_{f}=60^{\circ} \mathrm{C} ; T_{p}=20^{\circ} \mathrm{C}\end{array}$ & {$[55]$} \\
\hline TF450 & 0.178 & 0.45 & 0.138 & 80 & - & $\begin{array}{l}\sim 23 \\
\sim 27\end{array}$ & $\begin{array}{c}\text { Olive mill wastewater as feed; } T_{f}=70^{\circ} \mathrm{C} ; T_{p}=20^{\circ} \mathrm{C} \\
\text { distilled water as feed; } T_{f}=60^{\circ} \mathrm{C} ; T_{p}=20^{\circ} \mathrm{C}\end{array}$ & {$[55]$} \\
\hline $\mathrm{MCE}^{\mathrm{d}}$ & 100 & 0.05 & $\sim 24.1$ & 78 & 120.9 & $\sim 8$ & $\mathrm{NaCl} 1 \mathrm{M}$ as feed; $T_{f}=60^{\circ} \mathrm{C} ; T_{p}=20^{\circ} \mathrm{C}$ & {$[56]$} \\
\hline PVDF-HFP & 142 & 0.075 & - & 46 & - & 4.41 & $\begin{aligned} \mathrm{NaCl} 0.1 \mathrm{M} \text { as feed; } T_{f} & =65^{\circ} \mathrm{C} ; T_{p}=25^{\circ} \mathrm{C}(99.95 \% \text { salt } \\
& \text { retention) }\end{aligned}$ & {$[16]$} \\
\hline $\begin{array}{c}\text { Unsupported PVDF } \\
\text { (additive: acetone+ } \\
\mathrm{H}_{3} \mathrm{PO}_{4} \text { ) }\end{array}$ & 141 & 0.13 & - & 60 & 84 & 8.97 & $\begin{array}{l}\mathrm{NaCl} \mathrm{35g/L} \text { as feed; } T_{f}=50^{\circ} \mathrm{C} ; T_{p}=20^{\circ} \mathrm{C} \\
\text { (more than 99\% of salt retention) }\end{array}$ & {$[57]$} \\
\hline $\begin{array}{c}\text { Supported PVDF } \\
\text { (additive: acetone+ } \\
\mathrm{H}_{3} \mathrm{PO}_{4} \text { ) }\end{array}$ & 213 & 0.22 & - & 55 & 83 & 12.45 & $\begin{array}{l}\mathrm{NaCl} \mathrm{35g/L} \text { as feed; } T_{f}=50^{\circ} \mathrm{C} ; T_{p}=20^{\circ} \mathrm{C} \\
\text { (more than 99\% of salt retention) }\end{array}$ & {$[57]$} \\
\hline PVDF $^{\mathrm{e}}$ & 74 & 0.17 & - & 44 & 71.7 & $\sim 22$ & $\mathrm{NaCl} 35 \mathrm{~g} / \mathrm{L}$ as feed; $T_{f}=70^{\circ} \mathrm{C} ; T_{p}=20^{\circ} \mathrm{C}$ & [58] \\
\hline $\begin{array}{l}\text { Commercial PVDF } \\
\text { Micropillared- }\end{array}$ & 132 & 0.2 & 0.2 & - & 130 & $\sim 17.5$ & $\begin{array}{l}\text { Ratio of feed salt concentration to the initial } \\
\text { concentration }=1.9\end{array}$ & [59] \\
\hline$\left(\mathrm{MP}^{\mathrm{f}}\right) \mathrm{PVDF}$ & 263 & 0.1 & 0.2 & - & 155 & $\sim 22$ & $T_{f}=70^{\circ} \mathrm{C} ; T_{p}=20^{\circ} \mathrm{C}$ & \\
\hline CF-NA-A & 85 & 0.211 & 1.79 & 80 & 111 & $20^{\mathrm{g}} / 15^{\mathrm{h}}$ & \multirow{4}{*}{ 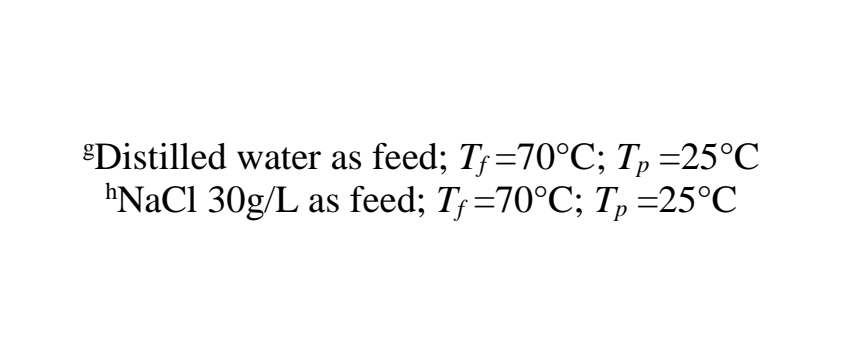 } & \multirow{4}{*}{$\begin{array}{l}\text { this } \\
\text { study }\end{array}$} \\
\hline PVP-0.2-AW & 70 & 0.265 & 1.67 & 79.4 & 93.5 & $16^{\mathrm{g} / 13^{\mathrm{h}}}$ & & \\
\hline PEG-0.2-A & 75 & 0.196 & 2.82 & 75.8 & 102.9 & $14^{\mathrm{g}} / 12.3^{\mathrm{h}}$ & & \\
\hline PEG-0.2-AW & 75 & 0.158 & 2.04 & 73.3 & 103.8 & $11^{\mathrm{g} / 8^{\mathrm{h}}}$ & & \\
\hline
\end{tabular}


${ }^{a}$ Commercial polyvinylidene fluoride (PVDF) flat-sheet membranes supplied by Millipore.

${ }^{b}$ Polyethylene (PE) based flat-sheet membrane supplied by Aquastill ${ }^{\circledR}$, Netherlands.

c Polytetrafluoroethylene supported by a polypropylene net supplied by Gelman.

${ }^{\mathrm{d}}$ Flat-sheet ultrafiltration mixed cellulose ester membrane supplied by Millipore.

e Membrane fabricated by novel method (bottom-up method) [58]

${ }^{\mathrm{f}}$ Membrane fabricated by micromolding phase separation [59] 


\subsection{Long-term DCMD performance}

To assess the long-term DCMD desalination stability, the prepared membranes with good performance (CF-NA-A, PVP-0.2-AW, PEG-0.2-A and PEG-0.2-AW) were selected and tested as stated earlier. The obtained DCMD permeate flux and salt separation factor of these membranes were plotted in Fig. 11. The permeate flux of the COP membrane prepared without any additive (CF-NA-A) was $14.50 \pm 0.36 \mathrm{~kg} / \mathrm{m}^{2} . \mathrm{h}$, which was maintained stable during $9 \mathrm{~h}$ of experimental test. However, the salt separation factor started to decline after $5 \mathrm{~h}$ although its value was greater than 99\%. In fact, this membrane exhibited a good porosity (80\%) and LEP value (1.96 bar). After $9 \mathrm{~h}$ of DCMD operation, the permeate flux was increased gradually to 25,36 and $44 \mathrm{~kg} / \mathrm{m}^{2} . \mathrm{h}$ during $12 \mathrm{~h}$ (for simplicity not shown in Fig.11) and it was observed that this membrane started first to be broken from its edges. Although the tensile strength of this membrane was reasonably good (Table 5) compared with other membranes found in the literature, its elongation at break was low and the sudden variation of the flowrate of the feed solution in the long-term DCMD set-up caused an increase of the hydrostatic pressure at the inlet of the membrane module feed side and the subsequent membrane breakage from its edges. It is promising that the COP membranes having a little bit more flexibility were not broken in the long-term DCMD set-up. However, the more flexible COP membranes, obtained in this study, were made by hydrophilic additive, which increases the risk of membrane pore wetting especially if this hydrophilic additive is not totally leached out from the membrane structure.

The membrane PVP-0.2-AW showed a stable permeate flux of $12.63 \pm 0.55 \mathrm{~kg} / \mathrm{m}^{2} . \mathrm{h}$ during 14 h of DCMD operation and a salt separation factor greater than $99.6 \%$ during 11 h of operation after which it started to decline reaching $99.2 \%$ after $14 \mathrm{~h}$. In contrast to the membrane CF-NA-A, 
1 the membrane PVP-0.2-AW was not broken. This may be attributed to its better flexibility due to

2 its better elongation at break. The Young's modulus $(E)$, which represents the membrane stiffness,

3 was found to be lower, $190 \mathrm{MPa}$ for the membrane PVP-0.2-AW compared to the other membranes

4 (CF-NA-A, PEG-0.2-A and PEG-0.2-AW, Table 5). However, it was detected a gradual increase

5 of the permeate flux of the membrane PVP-0.2-AW with time up to $24 \mathrm{~kg} / \mathrm{m}^{2} . \mathrm{h}$ after $20 \mathrm{~h}$ DCMD

6 operation and the salt separation factor was decreased to $97.6 \%$. This indicated that pore wetting

7 occurred, which is also confirmed by its low $L E P$ value (i.e. 1.67 bar).

8 The permeate flux and the salt rejection of the membrane PEG-0.2-A exhibited good 9 desalination performance during $26 \mathrm{~h}$ of the operation. The permeate flux was maintained stable 10 at $12.26 \pm 0.45 \mathrm{~kg} / \mathrm{m}^{2}$.h without any change of the salt separation factor (i.e. 99.9\%) mainly due to 11 the good LEP of this membrane (2.82 bar). However, after this time the permeate flux suddenly 12 increased because the membrane was broken similar to what occurred to the membrane CF-NA-A 13 although its mechanical properties are better than those of the membrane CF-NA-A. As it was 14 shown in Table 5, the membrane PEG-0.2-A had almost similar tensile strength and Young`s 15 modulus to those of the membrane CF-NA-A and some improvement in the elongation at break.

16 Compared to the previous selected COP membranes, the lowest and longer stable DCMD 17 permeate flux was obtained for the membrane PEG-0.2-AW $\left(7.74 \pm 0.61 \mathrm{~kg} / \mathrm{m}^{2} . \mathrm{h}\right)$ with a salt 18 separation factor greater than $99.4 \%$ during $50 \mathrm{~h}$ operating time. The low permeate flux of this 19 membrane was expected due to its lower porosity (73.3\%) and pore size (158 nm) compared to the 20 other membranes, CF-NA-A, PVP-0.2-AW and PEG-0.2-A. After $55 \mathrm{~h}$ of operation, the salt 21 separation factor decreased to $98.9 \%$ and at $63 \mathrm{~h}$ it reached $98.2 \%$. This membrane was not broken 22 as it showed the best mechanical properties compared to the membranes CF-NA-A, PVP-0.2-AW 
1 and PEG-0.2-A (Table 5). Based on the low affinity of PEG-NS $m\left(R_{H S P}=18.02\right)$ compared to

2 PEG-S $\left(R_{H S P}=3.5\right)$ and the higher $R_{H S P}$ value of PEG-A/W compared to that of PEG-A (18.02

3 versus 10.65), the acetone/water was a weak coagulant compared to acetone. It was reported that

4 the use of a weak coagulant caused a slow solidification hindering therefore the formation of walls

5 between small droplets [60]. Then, some small droplets were combined to form a large droplet

6 resulting in large drop-shaped cavities in the sub-layer (Fig. 10) [60]. In this type of structure, the

7 complete removal of additive may be more difficult. Therefore, the reduction of the salt separation

8 factor may be attributed to membrane wetting due to the presence of some additives in the 9 membrane structure.

10 It is promising that the elongation at break of the COP membranes should be improved further 11 in order to prevent their breakage (compare the elongation at break of CF-NA-A with that of PVP12 0.2-AW in Table 5). The addition of hydrophilic additives improves the flexibility of the 13 membranes but it may result in membrane wetting if the additive is not fully leached out from the 14 membrane matrix. The use of inorganic nanoparticles can be an effective method to improve both 15 the elongation at break and MD performance and prevent wetting of COP membranes. 

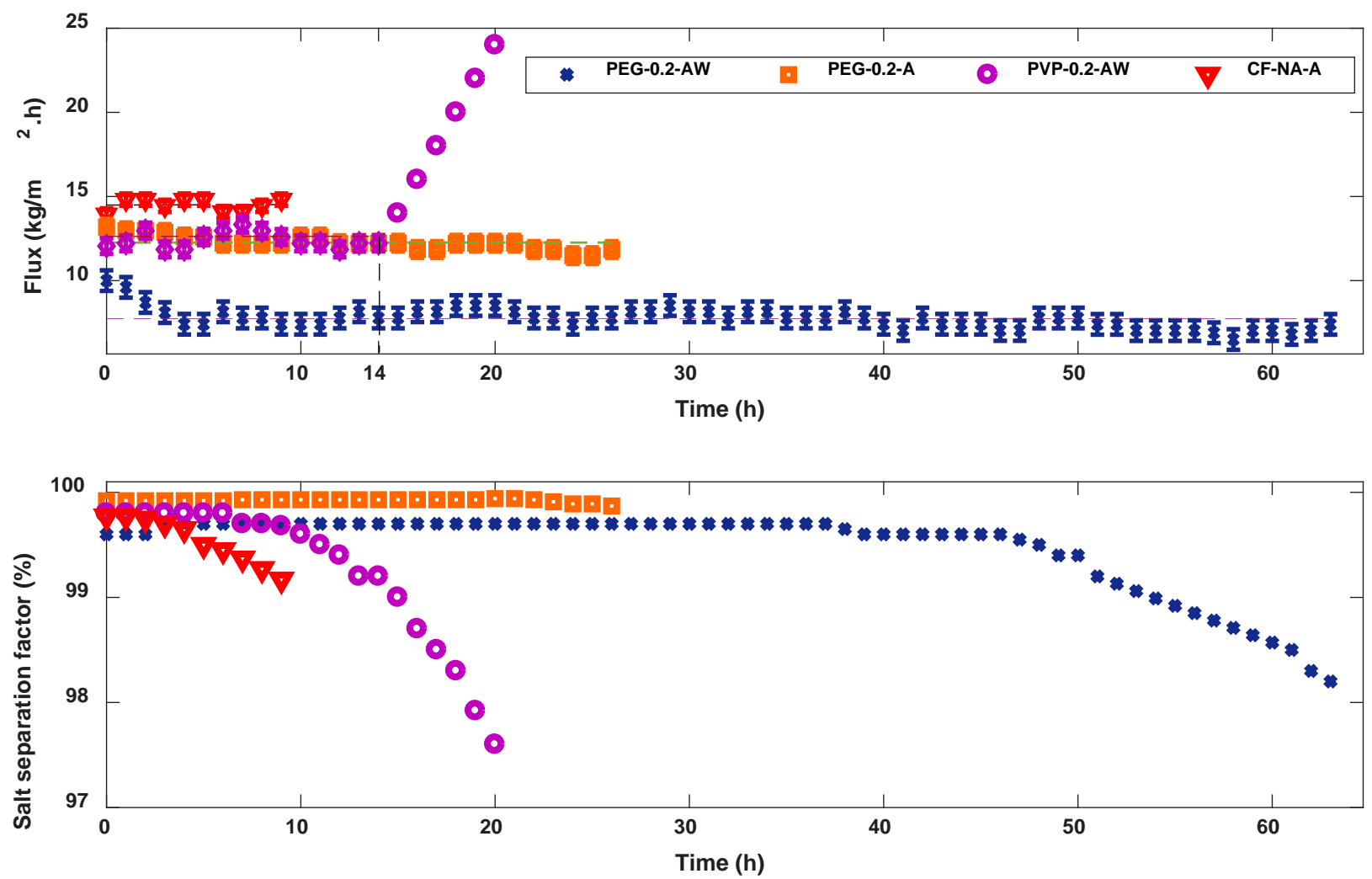

1

2

Fig. 11. Long-term DCMD performance of the COP membranes, CF-NA-A, PVP-0.2-AW, PEG0.2-A and PEG-0.2-AW: permeate flux (a) and salt separation factor (b) as a function of operating time.

\section{Conclusions}

Flat-sheet membranes were prepared for the first time from a novel and cheap engineering plastic (COP) via non-solvent induced phase separation technique (NIPS). Different types of solvents, coagulants and additives were examined and the resultant membranes were characterized for their use in desalination by direct contact membrane distillation (DCMD). It was found that the porosity of the prepared COP membrane lied in the range $50.0-82.3 \%$, their liquid entry pressure $(L E P)$ values were in the range 1.2 - 4.5 bar, their hydrophobic character was confirmed with water contact angle values up to $111^{\circ}$, their mean pore size varied from $0.158 \mu \mathrm{m}$ to $0.265 \mu \mathrm{m}$ and their 
1 tensile strength, elongation at break and Young's modulus were in the range 0.74-5.51 MPa, 3.3-

$27.9 \%$ and 29-237 MPa, respectively. These data are comparable with those of the porous

3 membranes commonly used in MD technology.

4 Short-term DCMD tests of the COP membrane prepared without any additive showed the 5 highest permeate flux (i.e. $20 \mathrm{~kg} \cdot \mathrm{m}^{-2} \mathrm{~h}^{-1}$ and $15 \mathrm{~kg} \cdot \mathrm{m}^{-2} \mathrm{~h}^{-1}$ when distilled water and $30 \mathrm{~g} / \mathrm{L}$ sodium

6 chloride aqueous solution were used as feed, respectively) with a high salt separation factor (i.e.

7 99.99\%). However, this membrane didn't show a good long-term DCMD performance due to its

8 high brittleness. This problem could be solved by using some additives, which resulted in a more

9 flexible COP membrane. Long-term DCMD of some selected membranes prepared with PVP and

10 PEG additives, showed pore wetting of the membrane prepared with PVP after $14 \mathrm{~h}$ of DCMD

11 operation whereas the membrane prepared with PEG with different coagulants (acetone and

12 acetone/water) exhibited more stable DCMD performance (i.e. 12.26 and $7.74 \mathrm{~kg} / \mathrm{m}^{2}$.h when using

13 acetone and acetone/water coagulants, respectively) during 24-50 h of desalination operation

14 without any significant changes of the salt separation factor. In general, this research study proved

15 that COP can be successfully used as a new candidate polymer in MD membrane engineering and

16 MD applications. More research studies are needed to improve the MD performance of the new

17 candidate COP membrane.

\section{Acknowledgments}

19 The authors gratefully acknowledge the financial support of the Spanish Ministry of Economy and

20 Competitiveness through its project CTM2015-65348-C2-2-R, the Spanish Ministry of Science,

21 Innovation and Universities through its project RTI2018-096042-B-C22 and also Sarkhoon and

22 Qeshm Gas Refinery Company of Iran (No. 266270). 


\section{References}

2 [1] T. Tong, M. Elimelech, The global rise of zero liquid discharge for wastewater management: 3 drivers, technologies, and future directions, Environ. Sci. Technol. 50 (2016) 6846-6855. 4 https://doi.org/10.1021/acs.est.6b01000.

[2] M. Hardikar, I. Marquez, and A. Achilli, Emerging investigator series: Membrane Distillation and high salinity: Analysis and Implications, Environ. Sci.: Water Res. Technol., 6 (2020) 15381552.

[3] M. Khayet, T. Matsuura, Membrane distillation: principles and applications, Elsevier (2011).

[4] M. Khayet, C. Cojocaru, C. García-Payo, Application of response surface methodology and 5673-85. https://doi.org/10.1021/ie070446p.

[5] M. Khayet, A. Velázquez and J. I. Mengual, Modelling mass transport through a porous partition: effect of pore size distribution, J. Non-Equilib. Thermodyn. 29 (2004) 279-299. https://doi.org/10.1515/JNETDY.2004.055.

[6] M. Khayet, Membranes and theoretical modeling of membrane distillation: a review, Adv. Colloid. Interface. Sci. 164 (2011) 56-88. https://doi.org/10.1016/j.cis.2010.09.005.

[7] P. Wang, T.S. Chung, Recent advances in membrane distillation processes: membrane development, configuration design and application exploring, J. Membr. Sci. 474 (2015) 39-56. https://doi.org/10.1016/j.memsci.2014.09.016

[8] M.S. El-Bourawi, Z. Ding, R. Ma, M. Khayet, A framework for better understanding membrane distillation separation process, J. Membr. Sci. 285 (2006) 4-29. https://doi.org/10.1016/j.memsci.2006.08.002.

[9] K. J. Lu, Y. Chen, T.-Sh. Chung, Design of omniphobic interfaces for membrane distillation - A review, Water Res. 162 (2019) 64-77.

[10] W. Qing, Y. Wu, X. Li, X. Shi, S. Shao, Y. Mei, W. Zhang, Ch. Y. Tang, Omniphobic PVDF nanofibrous membrane for superior anti-wetting performance in direct contact membrane distillation, J. Membr. Sci. 608 (2020) 118226.

[11] N. Tang, Q. Jia, H. Zhang, J. Li, Sh. Cao, Preparation and morphological characterization of narrow pore size distributed polypropylene hydrophobic membranes for vacuum membrane distillation via thermally induced phase separation, Desalination. 256 (2010) 27-36. https://doi.org/10.1016/j.desal.2010.02.024.

[12] H. J. Hwang, K. He, S. Gray, J. Zhang, I. S. Moon, Direct contact membrane distillation (DCMD): experimental study on the commercial PTFE membrane and modeling, J. Membr. Sci. 371 (2011) 90-98. https://doi.org/10.1016/j.memsci.2011.01.020. 
[13] K. Chen, Ch. Xiao, Q. Huang, H. Liu, H. Liu, Y. Wu, Zh. Liu, Study on vacuum membrane distillation (VMD) using FEP hollow fiber membrane. Desalination 375 (2015) 24-32. https://doi.org/10.1016/j.desal.2015.07.021.

[14] J.M. Li, Zh.K. Xu, Zh.M. Liu, W.F. Yuan, H. Xiang, Sh. Y. Wang, Y.Y. Xu, Microporous polypropylene and polyethylene hollow fiber membranes. Part 3. Experimental studies on membrane distillation for desalination, Desalination. 155 (2003) 153-156. https://doi.org/10.1016/S0011-9164(03)00292-3.

[15] M. Khayet, T. Matsuura, Preparation and Characterization of Polyvinylidene Fluoride Membranes for Membrane Distillation, Ind. Eng. Chem. Res. 40 (24) (2001) 5710-5718. https://doi.org/10.1021/ie010553y.

[16] M. Khayet, C. Cojocaru, M.C. García-Payo, Experimental design and optimization of asymmetric flat-sheet membranes prepared for direct contact membrane distillation, J. Membr. Sci. 351 (2010) 234-245. https://doi.org/10.1016/j.memsci.2010.01.057

[17] C. Feng, B. Shi, G. Li, Y. Wu, Preparation and properties of microporous membrane from poly (-vinylidene fluoride-co-tetrafluoroethylene) (F2.4) for membrane distillation, J. Membr. Sci. 237 (1-2) (2004) 15-24. https://doi.org/10.1016/j.memsci.2004.02.007.

[18] J. Wang, L.B. Zheng, Z.J. Wu, Y. Zhang, X.H. Zhang, Fabrication of hydrophobic flat sheet and hollow fiber membranes from PVDF and PVDF-CTFE for membrane distillation, J. Membr. Sci. 497 (2016) 183-193. https://doi.org/10.1016/j.memsci.2015.09.024.

[19] L. Eykens, K. De Sitter, C. Dotremont, L. Pinoy, B. Van der Bruggen, Membrane synthesis for membrane distillation: A review, Sep. Purif. Technol. 182 (2017) 36-51. https://doi.org/10.1016/j.seppur.2017.03.035.

[20] W. S. Rosine Lago, C. Aymes-Chodur, A. P. Ahoussou, and N. Yagoubi, Physico-chemical ageing of ethylene-norbornene copolymers: a review, J. Mater. Sci. 52 (2017) 6879-6904. https://doi.org/10.1007/s10853-017-0925-9.

[21] M. Yamazaki, Industrialization and application development of cyclo-olefin polymer. J. Mol. Catal. A-Chem. 213(1) (2004) 81-87. https://doi.org/10.1016/j.molcata.2003.10.058.

[22] Ch.Ch. Hu, K.R. Lee, R.Ch. Ruaan, Y.C. Jean, J.Y. Lai, Gas separation properties in cyclic olefin copolymer membrane studied by positron annihilation, sorption, and gas permeation, J. Membr. Sci. (2006) 192-199. https://doi.org/10.1016/j.memsci.2005.05.034.

[23] M. Doğu and N. Ercan, High performance cyclic olefin copolymer (COC) membranes prepared with melt processing method and using of surface modified graphitic nanosheets for $\mathrm{H}_{2} / \mathrm{CH}_{4}$ and $\mathrm{H}_{2} / \mathrm{CO}_{2}$ separation, Chem. Eng. Res. Des. 109 (2016) 455-463. https://doi.org/10.1016/j.cherd.2016.02.021.

[24] M. Essalhi, M. Khayet, Self-sustained webs of polyvinylidene fluoride electrospun nanofibers: effects of polymer concentration and desalination by direct contact membrane distillation, J. Membr. Sci. 454 (2014) 133-143. https://doi.org/10.1016/j.memsci.2013.11.056. 
[25] M. Khayet, C.Y. Feng, K.C. Khulbe, T. Matsuura, Preparation and characterization of polyvinylidene fluoride hollow fiber membranes for ultrafiltration, Polymer. 43 (2002) 38793890. https://doi.org/10.1016/S0032-3861(02)00237-9.

[26] M. Khayet, T. Matsuura, Determination of surface and bulk pore sizes of flat-sheet and hollow fiber membranes by atomic force microscopy, gas permeation and solute transport methods, Desalination. 158 (2003) 57-64. https://doi.org/10.1016/S0011-9164(03)00433-8.

[27] M. Essalhi, M. Khayet, Self-sustained webs of polyvinylidene fluoride electrospun nanofibers at different electrospinning times: 1. Desalination by direct contact membrane distillation, J. Membr. Sci. 433 (2013) 167-179. https://doi.org/10.1016/j.memsci.2013.01.023.

[28] C.M. Hansen, Hansen solubility parameters: A User's Handbook, 2nd edition, CRC Press, Taylor \& Francis Group, Boca Ratón, FL (2007).

[29] L. García-Fernández, M.C. García-Payo, M. Khayet, Mechanism of formation of hollow fiber membranes for membrane distillation: 1. Inner coagulation power effect on morphological characteristics, J. Membr. Sci. $542 \quad$ (2017) 456-468. https://doi.org/10.1016/j.memsci.2017.03.036.

[30] A.F.M. Barton, Handbook of polymer-liquid interaction parameters and solubility parameters, Chapter 24 (1990).

[31] B. Wang, Th. Kuo, D. S. Mcwilliams, F. W. Harris, T. C. Germroth, J. Jing, D. Zhang and X. Zheng, Optical films cast from styrenic fluoropolymer solutions, US20120283371 (2012), Application Number: 13461372, (also published as: WO2013165806A1, CN104245825 and JP2015517585) (2012).

[32] A. Yamasaki, R. K. Tyaci, A. Fouda, and T. Matsuura, Effect of evaporation time on the pervaporation characteristics through homogeneous aromatic polyamide membranes. I. pure water permeation and membrane characterization by sorption measurements, J. Appl. Polym. Sci. 57 (1995) 1473-1481. https://doi.org/10.1002/app.1995.070571207.

[33] G. Friedrich, A. Driancourt, C. Noel and L. Monnerie, Asymmetric reverse osmosis and ultrafiltration membranes prepared from sulfonated polysulfone, Desalination. 36 (1981) 39. https://doi.org/10.1016/S0011-9164(00)88630-0.

[34] S. Hyun Yoo, J. Hak Kim, J. Young Jho, J. Won, Y. S. Kang, Influence of the addition of PVP on the morphology of asymmetric polyimide phase inversion membranes: effect of PVP molecular weight, J. Membr. Sci. 236 (2004) 203-207. https://doi.org/10.1016/j.memsci.2004.02.017.

[35] B. Jung, J. K. Yoon, B. Kim, H. W. Rhee, Effect of molecular weight of polymeric additives on formation, permeation properties and hypochlorite treatment of asymmetric polyacrylonitrile membranes. J. Membr. Sci. 24 (2004) 243. https://doi.org/10.1016/j.memsci.2004.06.011.

[36] E. Fontananova, J.C. Jansen, A. Cristiano, E. Curcio, E. Drioli, Effect of additives in the casting solution on the formation of PVDF membranes, Desalination 192 (2006) 190-197. https://doi.org/10.1016/j.desal.2005.09.021. 
[37] S. Simone, A. Figoli, A. Criscuoli, M.C. Carnevale, A. Rosselli, E. Drioli, Preparation of hollow fibre membranes from PVDF/PVP blends and their application in VMD, J. Membr. Sci. 364 (2010) 219-232. https://doi.org/10.1016/j.memsci.2010.08.013.

[38] A. B. Alayande, M. Obaid, H.-W. Yu, In S. Kim, High-flux ultrafiltration membrane with open porous hydrophilic structure using dual pore formers, Chemosphere. 227 (2019) 662-669. https://doi.org/10.1016/j.chemosphere.2019.04.081.

[39] M. Tomaszewska, Preparation and properties of flat-sheet membranes from poly (vinylidene fluoride) for membrane distillation, Desalination. 104 (1996) 1-11. https://doi.org/10.1016/00119164(96)00020-3.

[40] D. Hou, J. Wang, X. Sun, Zh. Ji, Zh. Luan, Preparation and properties of PVDF composite hollow fiber membranes for desalination through direct contact membrane distillation, J. Membr. Sci. 405-406 (2012)185-200. https://doi.org/10.1016/j.memsci.2012.03.008.

[41] A. Zolfaghari, S. A. Mousavi, R. B. Bozarjomehri, F. Bakhtiari, Gas-liquid membrane contactors: Effects of polymer concentration and solvent type on pore size distribution, J. Membr. Sci. 563 (2018) 813-819. https://doi.org/10.1016/j.memsci.2018.05.034.

[42] H.A. Tsai, R.Ch. Ruaan, D.M. Wang, J.Y. Lai, Effect of temperature and span series surfactant on the structure of polysulfone membranes, J. Appl. Polym. Sci. 86 (2002) 166-173. https://doi.org/10.1002/app.10932.

[43] R.M. Boom, I.M. Wienk, Th. van den Boomgaard, C.A. Smolders, Microstructures in phase inversion membranes. Part 2. The role of a polymeric additive, J. Membr. Sci. 73 (1992) 277. https://doi.org/10.1016/0376-7388(92)80135-7.

[44] I. C. Kim, K. H. Lee, Effect of poly (ethylene glycol) 200 on the formation of a polyetherimide asymmetric membrane and its performance in aqueous solvent mixture permeation, J. Membr. Sci. 230 (2004) 183. https://doi.org/10.1016/j.memsci.2003.11.002.

[45] P. Van De Witte, P.J. Dijkstra, J.W.A. Van Den Berg, J. Feijen, Phase separation processes in polymer solutions in relation to membrane formation, J. Membr. Sci. 117 (1996) 1-31. https://doi.org/10.1016/0376-7388(96)00088-9.

[46] K.W. Lee, B.K. Seo, S.T. Nam, M.J. Han, Trade-off between thermodynamic enhancement and kinetic hindrance during phase inversion in the preparation of polysulfone membranes, Desalination 159 (2003) 289-296. https://doi.org/10.1016/S0011-9164(03)90081-6.

[47] A. Gao, F. Liu, H. Shi, L. Xue, Controllable transition from finger-like pores to interconnected pores of PLLA membranes, J. Membr. Sci. 478 (2015) 96-104. https://doi.org/10.1016/j.memsci.2015.01.004.

[48] Q. Ge, L. Ding, T. Wu, G. Xu, F. Yang, M. Xiang, Effect of surfactant on morphology and pore size of polysulfone membrane, J. Polym. Res. 25 (2018) 21. https://doi.org/10.1007/s10965017-1410-5. 
[49] J.Y. Lai, F. Ch. Lin, Ch. Ch, Wang, D. M. Wang, Effect of nonsolvent additives on the porosity and morphology of asymmetric TPX membranes, J. Membr. Sci. 118 (1996) 49-61. https://doi.org/10.1016/0376-7388(96)00084-1.

[50] H.A. Tsai, D.H. Huang, R.Ch. Ruaan, and J.Y. Lai, Mechanical properties of asymmetric polysulfone membranes containing surfactant as additives, Ind. Eng. Chem. Res. 40 (2001) 59175922. https://doi.org/10.1021/ie010026e.

[51] J. Phattaranawik, R. Jiraratananon, A.G. Fane, Effect of pore size distribution and air flux on mass transport in direct contact membrane distillation, J. Membr. Sci. 215 (2003) 75-85. https://doi.org/10.1016/S0376-7388(02)00603-8.

[52] J. Phattaranawik, R. Jiraratananon, A.G. Fane. Effects of net-type spacers on heat and mass transfer in direct contact membrane distillation and comparison with ultrafiltration studies, J. Membr. Sci. 217 (2003) 193-206. https://doi.org/10.1016/S0376-7388(03)00130-3.

[53] M. Laqbaqbi, M.C. García-Payo, M. Khayet, J. El Kharraz, M. Chaouch, Application of direct contact membrane distillation for textile wastewater treatment and fouling study, Sep. Purif. Technol. 209 (2019) 815-825. https://doi.org/10.1016/j.seppur.2018.09.031.

[54] A. Ali, A. Criscuoli, F. Macedonio, E. Drioli, A comparative analysis of flat sheet and capillary membranes for membrane distillation applications, Desalination. 456 (2019) 1-12. https://doi.org/10.1016/j.desal.2019.01.006.

[55] A. El-Abbassi, H. Kiai, A. Hafidi, M.C. García-Payo, M. Khayet, Treatment of olive mill wastewater by membrane distillation using polytetrafluoroethylene membranes, Sep. Purif. Technol. 98 (2012) 55-61. http://dx.doi.org/10.1016/j.seppur.2012.06.026.

[56] E. Shaulsky, V. Karanikola, A. P. Straub, A. Deshmukh, I. Zucker, M. Elimelech, Asymmetric membranes for membrane distillation and thermo-osmotic energy conversion, Desalination. 452 (2019) 141-148. https://doi.org/10.1016/j.desal.2018.11.005.

[57] D. Hou, H. Fan, Q. Jiang, J. Wang, X. Zhang, Preparation and characterization of PVDF flatsheet membranes for direct contact membrane distillation, Sep. Purif. Technol. 135(1) (2014) 211222. https://doi.org/10.1016/j.seppur.2014.08.023.

[58] M. Tian, Sh. Yuan, F. Decaesstecker, J. Zhu, A. Volodine, B. Van der Bruggen, One-step fabrication of isotropic poly (vinylidene fluoride) membranes for direct contact membrane $\begin{array}{lllll}\text { distillation } & \text { (DCMD), } & \text { Desalination. } & 477 & \text { (2020) }\end{array}$ https://doi.org/10.1016/j.desal.2019.114265.

[59] Z. Xiao, H. Guo, H. He, Y. Liu, X. Li, Y. Zhang, H. Yin, A. V. Volkov, T. He, Unprecedented scaling/fouling resistance of omniphobic polyvinylidene fluoride membrane with silica nanoparticle coated micropillars in direct contact membrane distillation, J. Membr. Sci. 599 (2020) 117819. https://doi.org/10.1016/j.memsci.2020.117819.

[60] A. Xu, A. Yang, S. Young, D. deMontigny, and P. Tontiwachwuthikul, Effect of internal coagulant on effectiveness of polyvinylidene fluoride membrane for carbon dioxide separation and absorption, J. Memb. Sci. 311 (2008) 153- 158. https://doi.org/10.1016/j.memsci.2007.12.008 